\title{
FRANCIA Y EL LIBRO BLANCO DE 2013: ENTRE CONTINUIDAD Y NUEVOS DESAFÍOS ${ }^{1}$

Lisa Gabrielle Muñoz

Fabián Cristancho Rodríguez

William Medina Díaz

\section{Introducción: "Francia, una potencia europea con influencia global"}

La promulgación de la Ley de seguridad interior y lucha antiterrorista, del 30 de octubre del 2017, como continuidad al estado de emergencia en el cual Francia vivía desde noviembre del 2015, ilustra la voluntad del Estado francés por dotarse de herramientas para defenderse contra la amenaza terrorista y fortalecer su seguridad interior. A pesar de que esta ley fue la iniciativa del gobierno actual, del presidente Emmanuel Macron, se enmarca en la continuidad del último "Libro blanco de seguridad y defensa nacionales" publicado en el 2013 bajo la presidencia de François Hollande, objeto de análisis del presente capítulo.

La estrategia de seguridad y defensa nacional francesa se desarrolla en un escenario cambiante, determinado por el fenómeno de la globalización, el impacto de las amenazas tradicionales y los nuevos peligros emergentes del sistema globalizado en los escenarios local, nacional, regional e internacional.

Así como la globalización ha tenido efectos positivos y ha permitido la interconexión de la sociedad mundial y el intercambio de ideas, cultura y mercados, ha determinado el proceso de transformación de las amenazas a la seguridad nacional e internacional, y les ha brindado la capacidad de permear las fronteras debido a su

1 Capítulo de libro resultado del proyecto de investigación de la Maestría en Seguridad y Defensa Nacionales, titulado: "Desafíos y nuevos escenarios de la Seguridad Multidimensional en el contexto nacional, regional y hemisférico en el decenio 2015-2025”, el cual hace parte del Grupo de Investigación Centro de Gravedad de la Escuela Superior de Guerra "General Rafael Reyes Prieto", reconocido y categorizado en (A) por Colciencias, con el código COL0104976.

2 La traducción de los extractos del "Livre blanc sur la défense et sécurité nationale" (Défense et la Sécurité Nationale, s. f.), así como de los demás textos citados corresponden al autor de este capítulo. 
carácter intangible para los mecanismos de defensa nacional. De esta forma, ningún Estado es inmune a los efectos e impactos de la globalización, por esta razón, los Estados desarrollan políticas y estrategias para garantizar su seguridad y defensa nacionales (Dufort, 2017; Álvarez Calderón \& Rodríguez Beltrán, 2018).

Francia (figura 1) es uno de los actores más dinámicos e influyentes en el sistema internacional, es parte de los principales organismos intergubernamentales de impacto político, económico y militar a nivel regional y global. Ha adquirido un protagonismo particular y ha asumido con responsabilidad sus compromisos políticos, económicos, militares y humanitarios. Está ubicada en Europa occidental y limita con Andorra, Bélgica, Alemania, Italia, Luxemburgo, Mónaco, España y Suiza. Posee una extensión territorial continental de 551.500 kilómetros cuadrados y territorios de ultramar como Guyana Francesa, Guadalupe, Martinica, Mayotte y Reunión, entre otros. Su población a julio de 2017 alcanzaba los 67.106.161 habitantes. Su gobierno se rige por un régimen semipresidencial (Central Intelligence Agency, 2018).

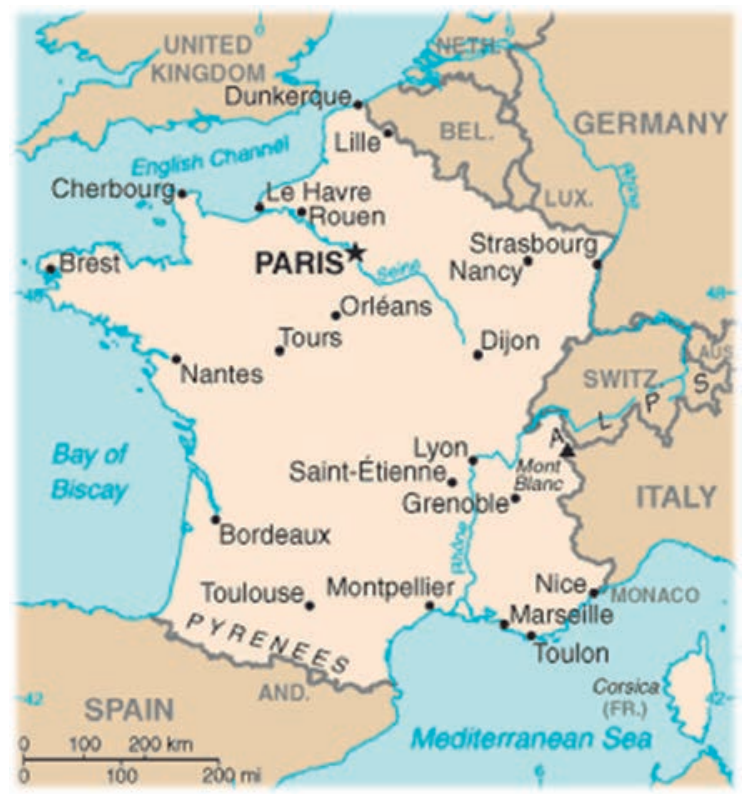

Figura 1. República de Francia.

Fuente: Central Intelligence Agency. The World Factbook (2018).

A lo largo de la historia, la soberanía y seguridad francesas se han visto amenazadas por cuenta de su ubicación geográfica estratégica, que se caracteriza por su cercanía a tres mares (Atlántico, Mediterráneo y el mar del Norte), ser el paso de 
la gran mayoría de las rutas áreas entre Europa, América, África y Oriente Medio, y su presencia en áreas estratégicas alrededor del globo, debido a sus posesiones de ultramar (figura 2). Lo que conforma la segunda zona económica exclusiva (zee) más grande del mundo, con un área de 11 millones de $\mathrm{km}^{2}$ (The French White Paper on Defense and National Security, 2008).

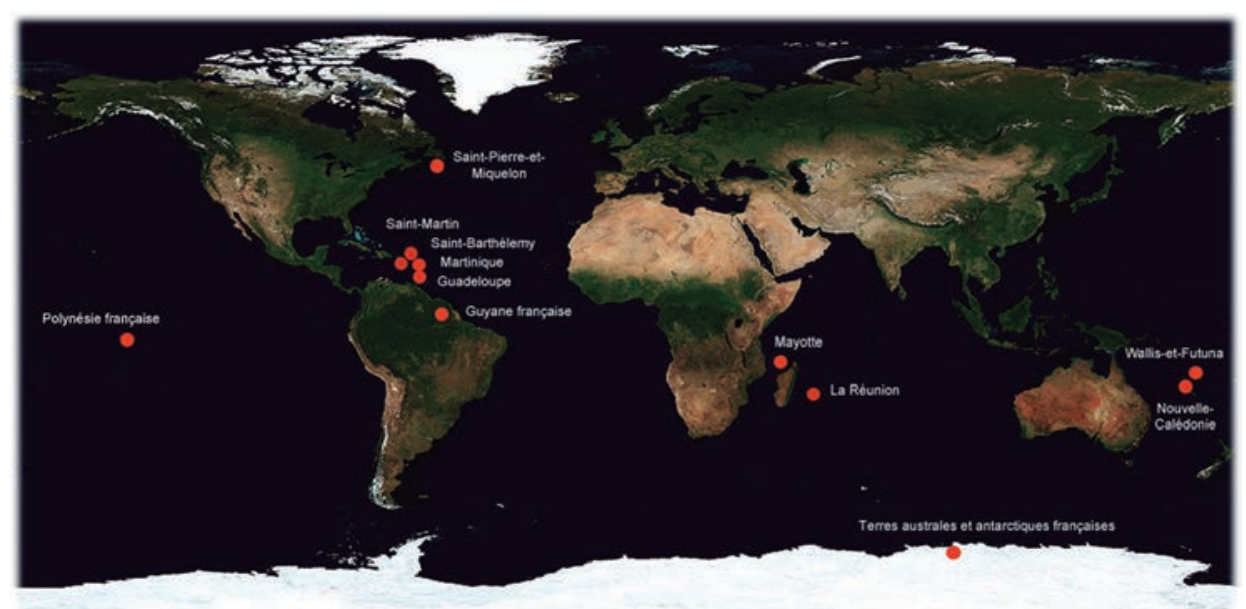

Figura 2. Territorios de Ultramar República de Francia.

Fuente: Répartition des territoires d'Outre-mer (Muséum National d'Histoire Naturelle, s. f.)

Debido a la participación del Estado francés en importantes procesos históricos, económicos, culturales y políticos a nivel regional e internacional, se ha convertido en uno de los actores protagónicos del sistema internacional. Francia es una de las grandes potencias mundiales y ha participado destacadamente en diferentes escenarios políticos y económicos, lo que le ha convertido en miembro activo de las principales organizaciones y grupos intergubernamentales en el sistema internacional, como lo es el Consejo de Seguridad de las Naciones Unidas; la Organización del Tratado del Atlántico Norte (otan); la Unión Europea; el G-7 y el G-8; la Agencia Internacional de Energía Atómica (oiea); Interpol; la Organización para la Cooperación y el Desarrollo Económico (ocde); la Organización para la Prohibición de las Armas Químicas (opcw); la Organización para la Seguridad y Cooperación en Europa (osce) y el Club de París, entre otros.

Como consecuencia de este protagonismo, su estatus y las dinámicas del sistema internacional, Francia se ha visto en la obligación de diseñar estrategias y políticas, a lo largo de su historia, con el fin de garantizar su seguridad, supervivencia y soberanía nacional frente a diversos desafíos cada vez más imprevisibles. Uno de los principales objetivos geopolíticos de Francia está direccionado a la cons- 
tante búsqueda del liderazgo regional, mediante la unificación y consolidación de la Unión Europea, para limitar de esta forma el dominio anglosajón y la intervención en los asuntos europeos.

Además, ha gestionado un liderazgo predominante en el interior de la organización y ha fortalecido su participación en organismos multilaterales de seguridad colectiva, como la otan, lo que ha incrementado su peso político en Europa (Brzezisnski, 1998), que no es otra cosa que el complemento a la evolución estratégica y la adaptación de Francia a los cambios generados en el escenario de la seguridad internacional. De esta forma, si Francia busca mantenerse como potencia, así como ampliar y fortalecer su influencia política, deberá tomar ventaja de la coyuntura europea, pues, con el Brexit, se ha convertido en el único miembro de la Unión Europea dotado de armas nucleares y con asiento en el Consejo de Seguridad.

Los objetivos estratégicos para Francia se establecen en pro de preservar su independencia, la soberanía de la nación y asegurar la legitimidad de las acciones tanto en el plano nacional como en el internacional. De igual forma, se pueden identificar imperativos geopolíticos como: proteger el territorio nacional y a los ciudadanos franceses, tanto en Europa como en territorios de ultramar; garantizar, junto con aliados y socios, la seguridad europea y euroatlántica; estabilizar, en conjunto con los aliados y socios, la vecindad europea; participar en la estabilidad de Medio Oriente y del Golfo Pérsico (The French White Paper on Defense and National Security, 2013).

La estrategia de defensa y seguridad nacional francesa —soportada en acciones estratégicas, la implementación de políticas de Estado (como la Ley de Programación Militar) y los planes nacionales como el Vigipirate- está diseñada para identificar las amenazas, desarrollar capacidades e implementar mecanismos de protección con el objetivo de mantener su independencia militar estratégica y asegurar la legitimidad de sus acciones a nivel regional e internacional.

\section{Francia y el Libro blanco de 2013: entre continuidad y nuevos desafíos}

\subsection{Análisis de los libros blancos de seguridad y defensa: una permanente adaptación al entorno internacional}

El Sistema Internacional (si) es el escenario donde los diferentes Estados se relacionan entre sí, a partir de principios y normas internacionales que permiten regular el comportamiento de los Estados y otros organismos internacionales. Holsti (1995) lo define como una "colección de entidades políticas independientes, 
que actúan con considerable frecuencia y conforme a procesos regularizados" (p. 327). El si está compuesto por una serie de actores o unidades políticas que al mantener relaciones entre sí son susceptibles de entrar en guerra (Aron, 1985). De igual forma, en el si se desarrollan fenómenos económicos, políticos, culturales, sociales y ambientales que tienen el potencial suficiente para atentar y vulnerar la seguridad de los Estados

Procesos como la globalización han generado nuevas dinámicas en la política internacional, fenómenos que continuamente evolucionan y mutan en el sistema internacional, lo que ha obligado a los Estados a adaptarse. En este sentido, es imperativo para los Estados el diseño e implementación de estrategias y políticas de seguridad nacional con el fin de salvaguardar sus intereses nacionales, entendiendo a la seguridad nacional como "la situación en la cual los intereses de la nación se hallan a cubierto de interferencias y perturbaciones substanciales" (cgfm, 1996, p. 21), con el fin de brindar bienestar a su población y así alcanzar los fines y objetivos nacionales. A este respecto Wolfers afirma que:

La seguridad constituye un valor que una nación puede poseer en menor o mayor medida, y al que puede aspirar a lograr en proporciones más considerables o inferiores. En este sentido, guarda enorme similitud con el poder o con la riqueza, otros dos valores de fundamental importancia en el ámbito de los asuntos internacionales. Sin embargo, en tanto que la riqueza mide el caudal de las posesiones materiales de una nación, y el poder su capacidad para controlar los actos de otras entidades, la seguridad por su parte, y en un sentido objetivo, mide la ausencia de amenazas a los valores adquiridos; y en un sentido subjetivo, mide la ausencia de temor a que dichos valores se vean atacados. En ambos sentidos, la seguridad de una nación puede recorrer una amplísima gama que presenta en uno de sus polos una inseguridad casi absoluta o la sensación de inseguridad, y en el otro extremo la seguridad casi absoluta o la ausencia de temor. (Wolfers, 1952, p. 484)

En este orden de ideas, en Francia, el primer libro blanco de defensa nacional fue elaborado en 1972 y se convirtió en un texto fundamental, pues definió las grandes orientaciones estratégicas de la defensa francesa para los años posteriores, a partir de las cuales fluyen las prioridades, los marcos y los medios para preservar la seguridad nacional. Igualmente, el libro blanco se constituye como la base de las leyes de programación militar que establecen las condiciones de aplicación del Libro. El texto está elaborado por una Comisión que reúne miembros del Parlamento, funcionarios de Ministerios de gran importancia (Asuntos exteriores, Economía, Interior, Defensa, Educación Superior), representantes de la administración nacional (prefectos, Secretario General para la Defensa y Seguridad Nacional), oficiales superiores de las Fuerzas Armadas organizados en varios 
comités. Igualmente, se realizan consultas a personalidades extranjeras, profesores e investigadores. Esta perspectiva interministerial y multidisciplinaria, aplicada a la elaboración de los libros, permite abarcar las diversas dimensiones de la seguridad y construir una estrategia de defensa integral.

De esta forma, los gobiernos de François Mitterrand, Nicolas Sarkosy y François Hollande han desarrollado e implementado el Libro blanco de seguridad y defensa nacionales en los años 1994, 2008 y 2013, respectivamente.

El Libro blanco de defensa de 1994 tenía como eje central la "proyección" y acción a distancia del territorio nacional (The French White Paper on Defense and National Security, 2008). Su implementación se inscribe en un contexto internacional cambiante, donde el crecimiento de las diferencias de desarrollo económico va a convertirse en un factor determinante que puede aumentar el riesgo ante una fractura de las relaciones entre los países en desarrollo y los desarrollados, y donde el surgimiento de nuevas economías influyentes en el sistema internacional podría alterar las dinámicas de poder en el sistema económico internacional. Las denominadas brics (Brasil, Rusia, India, China y Sudáfrica) generaron un giro en la política económica del siglo xxi, por las capacidades de estos actores y la influencia que pueden ejercer, tanto a nivel internacional como a nivel regional, en los escenarios político, económico, social y cultural.

La desintegración de la urss se presenta como una amenaza para la estabilidad regional, en especial si se toma en cuenta el vacío de poder político, económico y militar generado en aquellos territorios de influencia soviética. Esto ha causado inestabilidad, tensiones políticas, étnicas y fronterizas debido a la emergencia de movimientos nacionalistas, especialmente en regiones como Europa central y Europa oriental. Como consecuencia de este escenario inestable, se desarrollan nuevos conflictos armados de grandes envergaduras como lo fue la guerra de Yugoslavia, en la cual los intereses de las potencias europeas se encontraban divididos entre aquellos partidarios de la continuidad de la Federación Yugoslava y los que buscaban su desintegración (González, 2001).

Tras la desintegración de la Unión Soviética surgen nuevos Estados con la capacidad de convertirse en actores activos de la política regional. Ucrania se proyecta como uno de estos actores gracias a detentar una posición geográfica estratégica, y poseer, a pesar de una modesta capacidad económica, una amplia capacidad militar en materia de arsenal nuclear, heredada de la urss. Este poder militar está compuesto por 4355 ojivas nucleares, lo que corresponde al 16,1\% del total del arsenal de la Unión Soviética. Por otra parte, posee capacidad propia para desarrollar armamento nuclear a mediano plazo (De Salazar, 2004), por lo cual se convertirá en un actor clave en Europa oriental, lo que llamará la atención de la Unión Europea y Rusia. 
Cabe mencionar que las amenazas presentes en el sistema de posguerra fría han sufrido mutaciones y cambios gracias a fenómenos como la globalización, el cual ha generado una mayor invisibilidad de aquellas, al adquirir un carácter transnacional. Algunas de estas amenazas son: tráfico de drogas, tráfico de armas, tráfico de personas, lavado de dinero, entre otras (Naím, 2004), que, debido a la globalización, han adquirido la capacidad de permear las fronteras estatales, alterar el orden socioeconómico y político de los Estados, y afectar la seguridad nacional.

En 2001, el ataque del 11 de septiembre en Nueva York demostró el nivel de vulnerabilidad, la débil capacidad de respuesta de los Estados y del mismo sistema internacional, ante los ataques de nuevas amenazas como el terrorismo, el cual, se ha convertido en uno de los mayores peligros para la seguridad, defensa y estabilidad del sistema internacional. Esto, debido a su capacidad de interconectar factores sociales y culturales vinculados con procesos migratorios, así como su potencial para permeabilizar las fronteras de los Estados haciendo uso de procesos y desarrollos tecnológicos novedosos.

De cara a los retos y amenazas provenientes del terrorismo internacional, el gobierno francés de Jacques Chirac ha desarrollado e implementado herramientas como resultado de la elaboración de la estrategia en defensa. Francia, siguiendo los lineamientos del Libro blanco de defensa de 1994, desarrolla su política con respecto a la seguridad interior frente al terrorismo en la cual establece que las fuerzas armadas francesas confrontan el terrorismo mediante dos misiones específicas: "la protección y control de los espacios nacionales y de los intereses franceses, que básicamente lleva a cabo en territorio nacional, y una segunda misión, que es llevar a cabo operaciones en el exterior para neutralizar la amenaza terrorista antes de que actúe" (Ballesteros, 2006), con el fin de garantizar el interés nacional y el bienestar de la población francesa.

Teniendo en cuenta la mutación constante de las amenazas en el escenario nacional e internacional, el gobierno francés, liderado por el presidente Nicolas Sarkosy, solicitó la realización de un nuevo Libro blanco en el año 2008. En primera instancia, para confrontar las nuevas amenazas y al nuevo escenario internacional del siglo xxi; el texto se encaminó a la institucionalización del proceso de defensa y seguridad nacional. Dentro de las acciones programadas a corto plazo se estableció la creación de un organismo que dirigiera y acompañara el proceso para la elaboración de políticas y estrategias de seguridad y defensa. En este sentido, se constituyó el Consejo de Defensa y Seguridad Nacional (cdsn) mediante el cual se buscaba dar mayor eficacia al proceso de elaboración de políticas públicas, en materia de seguridad, defensa y definición de las prioridades (The French White Paper on Defense and National Security, 2008). 
El aporte clave del Libro del 2008 radica en la conceptualización de una estrategia nacional de seguridad enfocada y dirigida a desarrollarse en la era de la globalización, que reconoce los principios básicos de las nuevas estrategias de seguridad nacional referentes a

actuar sobre los orígenes, la evolución y la manifestación de los problemas (anticipation-réactivité), disponer de variedad y cantidad de instrumentos para responder flexiblemente de acuerdo con la situación (capacité de montée en puissance) y tener la determinación de sobreponerse a sus efectos (résilience). (Arteaga, 2008)

Todo lo anterior, teniendo en cuenta que la globalización trae consigo tanto efectos positivos como negativos, y que en este nuevo contexto estratégico "la distinción entre seguridad interior y seguridad exterior tiende a desdibujarse" (Leira, 2008).

La difusión rápida de las crisis políticas, económicas y financieras; el aumento constante de flujos migratorios, de bienes, servicios y de capital genera la necesidad de estructurar una estrategia nacional que permita la comprensión de los orígenes y la evolución de las amenazas, con el fin de desarrollar instrumentos para responder ante las necesidades y amenazas transitorias y permanentes. Esta estrategia, a su vez, está articulada a cinco funciones estratégicas (figura 3) que, en conjunto, le permitirán al Estado francés alcanzar su seguridad nacional, siendo estas: conocimiento y anticipación; prevención; disuasión; protección; e intervención (The French White Paper on Defense and National Security, 2008).

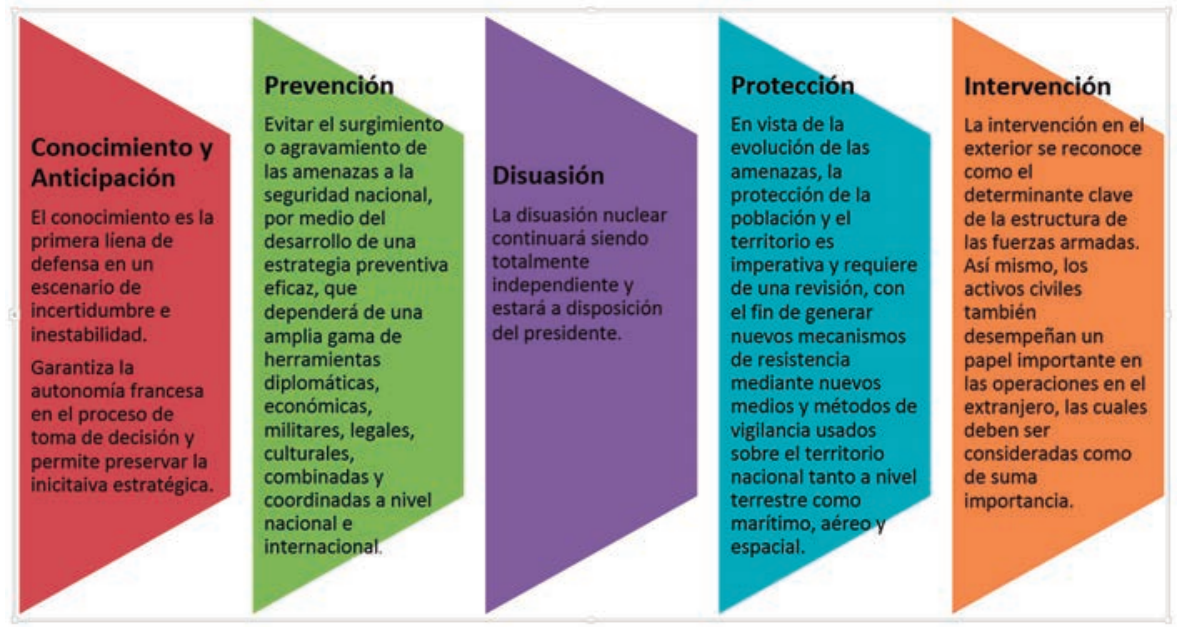

Figura 3. Las cinco funciones estratégicas de la seguridad y defensa francesa.

Fuente: elaboración propia a partir de la información en The French White Paper on Defence and National Security (2008). 
De acuerdo con lo expuesto en el Libro blanco de 2008, se resalta la importancia del arco del Atlántico al Océano Índico (figura 4), el cual se caracteriza por la inestabilidad, violencia interestatal y no estatal, así como por la proliferación y concentración de recursos energéticos, asuntos decisivos en el mantenimiento de la estabilidad.

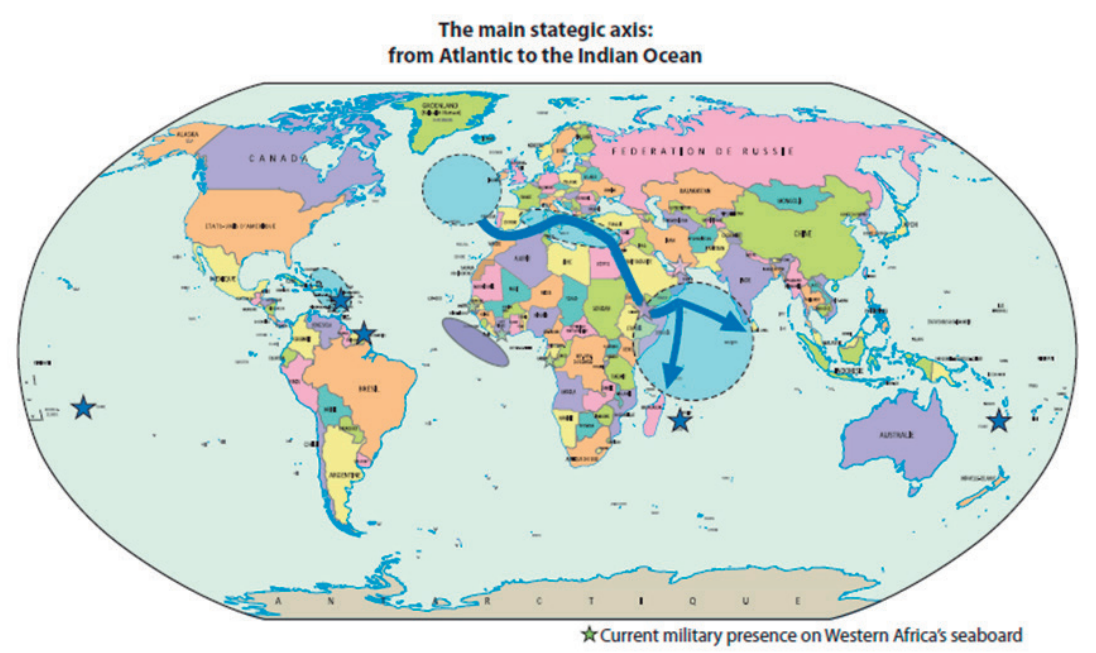

Figura 4: Arco del Atlántico al Océano Índico.

Fuente: Livre blanc sur la défense et la sécurité nationale (2008).

El periodo transcurrido entre el 2008 y el 2013 está marcado por una fuerte crisis económica mundial que trajo graves repercusiones para la economía francesa, pues limitó los recursos públicos destinados a la defensa y seguridad, lo que generó un riesgo frente a la independencia económica nacional. Diversos problemas derivados de la crisis, como el desempleo, han generado un efecto dominó a lo largo de Europa y han originado amenazas al marco de convivencia, esto ha elevado los índices de conflictividad, la xenofobia y la marginación social, de este modo atentan contra la seguridad colectiva regional (Castro, 2013). Esta crisis económica también tendrá graves repercusiones para los principales socios y aliados, como Estados Unidos, efectos que se verán reflejados en la disminución del gasto militar por el aumento de la selectividad frente a los compromisos internacionales, lo que genera presión sobre los países europeos, que tendrán que tomar más responsabilidades con respecto a la seguridad internacional.

Durante la segunda década del siglo xxi, Francia afronta nuevos procesos que tienen la capacidad de atentar contra los intereses nacionales, dentro de estos sobresale el fortalecimiento de la integración económica y financiera de la Unión 
Europea, pero bajo el estricto control de políticas reguladoras del gasto público establecidas por el Banco Central Europeo. Así mismo, el mundo árabe también se debe considerar como un escenario estratégico, debido a la inestabilidad de ciertas zonas, como lo demuestran los sucesos en Siria (The French White Paper on Defense and National Security, 2013).

En ese contexto, en el Libro blanco del 2013 el gobierno de François Hollande expone su interés en dar continuidad a una doctrina que ha servido para preservar la independencia y la soberanía, la cual ha permitido a Francia mantenerse en el sistema internacional como una de las principales potencias. Se resalta en el texto la capacidad que tiene el gobierno para tomar acciones, decisiones y medidas en favor del mantenimiento de un sistema internacional pacífico y estable, que permite fortalecer la seguridad internacional. De esta forma, la soberanía y la legitimidad internacional son dos pilares complementarios de la estrategia de defensa y seguridad nacional (The French White Paper on Defense and National Security, 2013).

\section{El Libro blanco de seguridad y defensa nacionales de 2013 y su análisis después del 2015}

\subsection{Apreciación de la política de defensa del Hexágono}

El "Libro blanco de seguridad y defensa nacionales del 2013" se desarrolló con una perspectiva a quince años, con el fin de establecer los principios, prioridades, el marco de acción y la disposición de los recursos necesarios para garantizar la seguridad del Estado (The French White Paper on Defence and National Security, 2013).

Con respecto al concepto de seguridad nacional, se retoma el expresado en el Libro blanco del 2008, también consagrado en la Ley del 29, de julio del 2009, que establece la necesidad de no solo centrarse en la protección del territorio nacional y su población frente a la agresión externa de otros Estados, sino que concibe que es imperativo para el Estado incluir la gestión de los riesgos y amenazas directos e indirectos que puedan atentar contra el Estado. (The French White Paper on Defence and National Security, 2013). De acuerdo con el Libro blanco del 2013, se entiende por riesgo cualquier peligro que no represente una hostilidad pero que puede generar un impacto en la seguridad nacional, como eventos políticos, riesgos naturales, industriales, sanitarios, ambientales y tecnológicos; por otra parte, una amenaza se entiende como cualquier situación en la cual Francia enfrente un escenario potencialmente hostil. 


\section{I.I APROXIMACIÓN A LA SEGURIDAD FRANCESA: LOS RETOS EUROPEOS FRENTE A} UNA VECINDAD INESTABLE

El sistema internacional de finales de la primera década del siglo xxi se caracterizó por una serie de cambios que incidirán de forma directa en las agendas de los Estados, debido al recrudecimiento de factores que atentan contra la seguridad internacional.

Las consecuencias de la crisis económica llevan Francia a buscar un punto de equilibrio entre el gasto público en seguridad y defensa y garantizar su independencia económica mediante una consolidación fiscal, con el fin de asegurar que el sistema de seguridad y defensa nacional sea compatible a largo plazo con las responsabilidades internacionales.

La crisis económica tuvo un fuerte impacto en la comunidad europea: generó afectaciones en los presupuestos y gastos del Estado, así como una pérdida de influencia, liderazgo y atractivo frente a las inversiones extranjeras. Asimismo, el impacto social de la crisis suscitó cuestionamientos y dudas dentro de la opinión pública respecto a la construcción europea, si se tiene en cuenta la dificultad de los líderes políticos para llegar a acuerdos y aportar soluciones a la crisis.

Por otra parte, el fenómeno conocido como Primavera Árabe, que consistió en una serie de revoluciones sociales y políticas acaecidas entre 2010 y 2011, tuvo un fuerte impacto en la opinión pública francesa y se convirtió rápidamente en un desafío para la seguridad y defensa nacional de Francia, en la medida en que alteraba su estrategia política y diplomática frente a los Estados del Medio Oriente y el norte de África —región de influencia en el Mediterráneo-, lo que generó rupturas estratégicas con estos países, con los cuales históricamente se habían establecido fuertes lazos de cooperación (Mikail, 2011).

Frente a la intensificación de los conflictos en esta región, Francia concibe como un reto de gran importancia la pacificación del mundo árabe, razón por la cual considera a Siria y Libia como zonas prioritarias y lleva a cabo operaciones exteriores denominadas 'Harmattan' (en Libia en el 2011) y 'Chammal' (en Siria en el 2014).

Igualmente, es importante considerar que los conflictos armados en el Medio Oriente llevaron al aumento desmedido de las migraciones —especialmente hacia Europa - en países como Francia, Alemania, España y Austria, entre otros. Dicho fenómeno de migración masiva se convirtió rápidamente en una crisis humanitaria a las puertas de la Unión Europea, lo que plantea también problemas de control de fronteras exteriores y de capacidades de recepción de la población migrante. 
De igual forma, el crecimiento económico y el reposicionamiento ruso han generado incertidumbre en el escenario internacional y regional por el crecimiento acelerado de su gasto militar, el proceso de modernización de su arsenal nuclear y el mejoramiento de sus fuerzas convencionales. No obstante, la estrategia rusa utilizada para demostrar su poder se complementa con el uso político de sus herramientas económicas — mediante la manipulación de los recursos energéticos- $y$, de otra parte, la influencia política en su entorno —al brindar apoyo y reconocimiento a movimientos secesionistas rusos establecidos en países periféricos- (The French White Paper on Defense and National Security, 2013).

La crisis de Ucrania y la incorporación de Crimea por parte de Rusia, que ocurrieron tras la publicación del Libro, confirmaron las dimensiones y el alcance de la estrategia rusa. La crisis ucraniana cristalizó las tensiones ruso-europeas debido a la importancia estratégica del país tanto para Rusia como para la Unión Europea, ambas partes teniendo la voluntad de incorporar a Ucrania en acuerdos comerciales y aduaneros.

La provincia autónoma de Crimea representa el punto más estratégico de esta zona, por arbitrar una importante base naval rusa en el puerto de Sebastopol, lo que constituye la salida al mar Negro para Moscú. La incorporación de Crimea a Rusia, en 2014, suscitó también fuertes preocupaciones tanto para la Unión Europea como para Francia, en especial si se toma en cuenta la facilidad con que Rusia absorbió otro territorio y el débil impacto de los intentos diplomáticos franco-alemanes para prevenir este evento.

Se evidencia también la preocupación del Estado francés por la proliferación de armas nucleares. Países como Corea del Norte y Pakistán, que han entrado en un proceso constante de modernización y desarrollo nuclear con fines militares, generan un riesgo de desestabilización de la región, esto mina lo alcanzado por el Tratado de No Proliferación y puede incentivar a otros Estados a entrar en el proceso armamentista. Este fenómeno se ha convertido en una amenaza potencial si se toma en cuenta que estos países están en la capacidad de desarrollar misiles balísticos con el alcance necesario para amenazar el continente europeo (The French White Paper on Defense and National Security, 2013).

Se puede considerar que varias de estas alteraciones al sistema y a la seguridad internacional no tendrán efecto o repercusión directa en la seguridad francesa. No obstante, son temas que sí involucran al Estado francés, por su voluntad de mantener la legitimidad de su posición y de su influencia al nivel mundial. Lo anterior, por un lado, porque Francia es una potencia regional, una economía estable, líder junto con Alemania de la construcción europea y, por otro lado, porque 
mantiene una influencia al nivel mundial, gracias a su poder geoestratégico y a sus aliados. Además, dispone de un asiento permanente en el Consejo de Seguridad de Naciones Unidas, lo que le permite tener voz y voto sobre temas de seguridad internacional.

Para evaluar el entorno de seguridad de los últimos años, tanto a nivel internacional como nacional, debe considerarse el papel del terrorismo. Entre otras razones, se puede considerar que Francia, por ser uno de los líderes del mundo occidental, con una sociedad ampliamente laicizada, que ha sido implicada en múltiples procesos internacionales, se ha convertido en uno de los blancos del terrorismo islámico. Esto, si se toma en consideración el desarrollo de la estrategia del "enemigo próximo, enemigo lejano", mediante la cual el terrorismo se desplaza de los territorios islámicos hacia aquellos territorios occidentales aliados de Estados Unidos (Daguzan, 2008).

Recientemente, un factor de preocupación ha sido el número creciente de ciudadanos franceses involucrados en las acciones de la organización del Estado Islámico en Siria y en Irak. Francia como país receptor de inmigrantes, especialmente provenientes de sus excolonias de África del Norte, tiene una población musulmana estimada entre el 7\% y el 9\% del total de la población francesa (Central Intelligence Agency, 2018). Según Gilles Kepel (2016), politólogo y especialista del islam, la instrumentalización política de temas como el racismo y la integración en la década de los ochenta, que impidió la representación de la población migrante en el sistema político francés, ha generado decepción y desesperanza dentro de la juventud, lo que la ha llevado, por una parte, a la delincuencia y la toxicomanía y, por otra, a ser más receptiva al discurso de movimientos religiosos radicales.

\section{I.2 FORTALECIMIENTO DE LA SEGURIDAD INTERIOR E INTENSIFICACIÓN} DE LAS INTERVENCIONES EXTERIORES

En la actualidad, Francia ha tenido una participación activa en la otan como respuesta a sus imperativos geopolíticos, centrados en mantener una identidad política y militar independiente, para así certificar una libertad de acción para garantizar su seguridad y el posicionamiento que ha logrado como potencia mundial, objetivos que van de la mano con la búsqueda de una Europa cada vez más sólida y unificada.

Teniendo en cuenta las mutaciones del sistema internacional y el periodo durante el cual Francia estuvo ausente del comando militar de la otan, se percibió la necesidad de un cambio, un posible paso de la independencia a una interdependencia — sin dejar de lado la soberanía nacional— que permitiera establecer 
lazos más fuertes entre las naciones occidentales, especialmente entre las europeas, con ello se conseguiría fortalecer la acción franco-europea frente a la posición estadounidense, por ello, a partir del 2009, Francia reingresa al comando militar de la organización (Pereira, 2009).

Frente a la multiplicación de los ataques terroristas, la respuesta del sistema internacional se ha visto evidenciada por las acciones de la otan y de la Unión Europea. Estados Unidos, el directo afectado en los ataques del 9-11, emprendió la guerra contra el terrorismo estableciendo una política exterior sostenida en la llamada "guerra preventiva", bajo el gobierno de George Bush. De igual forma, la otan invocó el artículo v del Tratado de Washington, por su parte, el Consejo Europeo dentro del marco de la Política Exterior y Seguridad Común (pesc) y la Política Europea de Seguridad y Defensa (pesd) establecieron la necesidad de combatir el terrorismo mediante un empleo más eficaz de las capacidades militares o civiles para proteger a la población civil (Ballesteros, 2006).

Como parte de la estrategia de respuesta al terrorismo, Francia ha llevado a cabo operaciones en el exterior dirigidas a identificar y prevenir cualquier amenaza terrorista. En septiembre del 2014, el presidente Francois Hollande anunció que Francia brindaría apoyo aéreo a las autoridades iraquíes para luchar contra la organización Estado Islámico (ei). Aunque Francia se había negado a intervenir en Siria —argumentando que ningún marco jurídico-político legitimaba una intervención- se anunciaron en septiembre 2015 los ataques aéreos en territorio sirio contra las posiciones del ei, lo que marca el giro de la política francesa en Medio Oriente (Le Monde, 2015). Cabe recordar que los atentados perpetrados en enero de 2015 contra el periódico Charlie Hedbo y el supermercado Hypercacher de la plaza de Vincennes en París, ilustraron la vulnerabilidad del territorio francés e impactaron la lógica defensiva implementada hasta el momento. Los ataques en Villejuif, Isère y el Thalys Ámsterdam, en París, orquestados desde Irak y Siria, contribuyeron a justificar la aplicación de la legítima defensa, establecida en el artículo 51 de la Carta de Naciones Unidas. De hecho, se pudo observar que los ataques aéreos contra la ciudad de Rakka, base del ei en Siria, sucedieron dos días después de los atentados de París del 13 de noviembre 2015, donde fallecieron 132 personas. Igualmente, el 15 de julio 2016, tras el atentado de Niza, el presidente francés declaró el refuerzo de las intervenciones en Irak y Siria.

Paralelamente, en la región del Sahel, Francia ha implementado una estrategia que busca desarrollar la capacidad de los Estados aliados para garantizar su seguridad de manera autónoma. Es el propósito de la 'Operación Barkhane', basada en una aproximación global (política, de seguridad y de desarrollo) y que trata de favo- 
recer que los países del G5 Sahel (Mauritania, Mali, Níger, Chad, Burkina Faso) se apropien de la lucha contra los Grupos Armados Terroristas (gat) en la zona de la franja sahelo-sahariana (Ministere des Armées, 2018).

Estas operaciones (figura 5) deberán estar respaldadas por cada uno de los servicios y las capacidades de las fuerzas militares, para articular así la estrategia de defensa con herramientas como la Ley de Programación Militar, mediante la cual "se contempla la posibilidad de una acción preventiva, siempre ante una situación de amenaza explícita y reconocida, es decir, no contra una amenaza potencial” (Ballesteros, 2006), con el objetivo de mantener una estabilidad en el sistema internacional y así mismo salvaguardar su interés nacional.

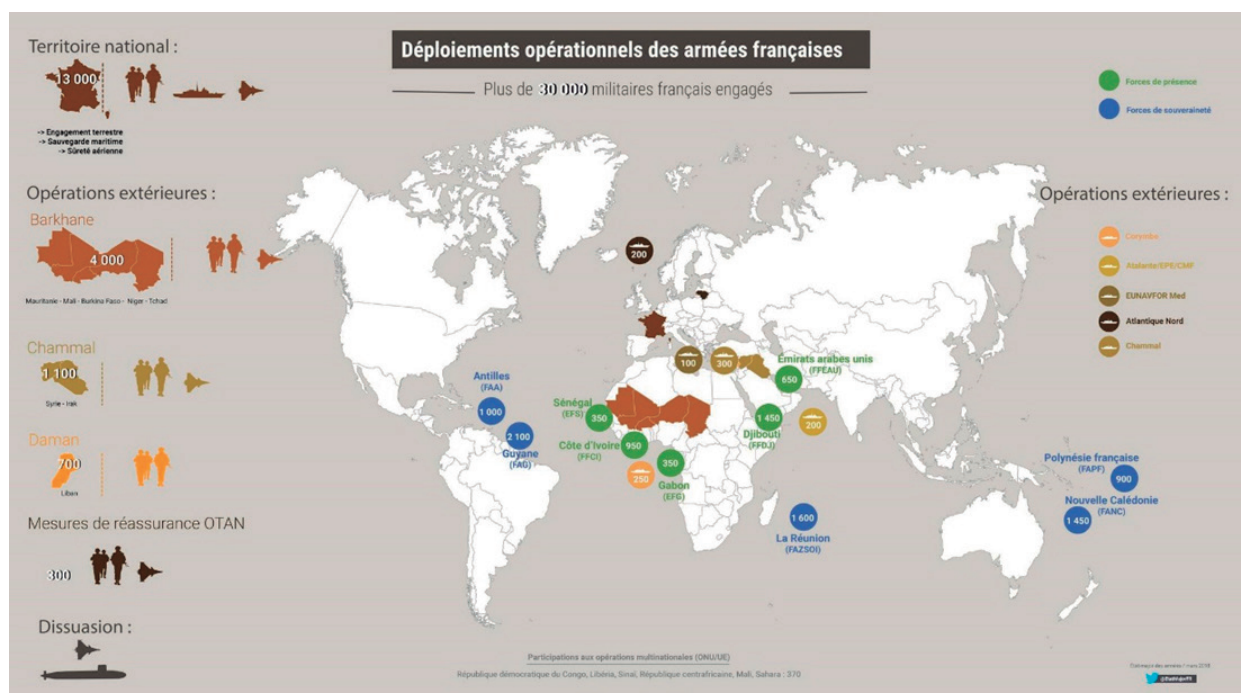

Figura 5. Operaciones Exteriores Fuerzas Armadas francesas.

Fuente: Ministère des Armées (2018).

A nivel interno se desarrollaron planes de acción denominados 'Pirate', conformados por medidas de alerta, así como de protección y de neutralización de carácter preventivo, lo que permitió desarrollar capacidad de respuesta frente a la amalgama de amenazas presentes en el sistema internacional (Ballesteros, 2006). Teniendo en cuenta el alcance de las amenazas y la diversidad de las mismas, se hizo necesaria la creación de una serie de planes enfocados en diferentes áreas y campos de acción donde las amenazas terroristas tienen la capacidad de atentar contra el Estado (Ballesteros, 2006).

Dentro de los planes de acción establecidos se encuentra el 'Plan Vigipirate', el cual fue actualizado en el 2003 y se articularía luego con la política de Seguridad 
Interior Frente al Terrorismo. El Plan Vigipirate se implementó a nivel interior con el fin de desarrollar una herramienta capaz de conseguir la disuasión por negación y con el objetivo de articular los esfuerzos de las fuerzas militares con las fuerzas policiales, bajo la dirección del ministro del Interior, en favor de la protección de la población, infraestructuras e instituciones y así tener capacidad de respuesta en caso de un atentado terrorista (Ballesteros, 2006). El Plan Vigipirate maneja un sistema de alerta representado en cuatro colores de acuerdo con el nivel de alerta estos son: amarillo, naranja, rojo y escarlata. Es solo en marzo del 2012, con los ataques terroristas perpetrados por Mohamed Merah en Toulouse, que el nivel escarlata es activado por primera y única vez (Le Monde, 2016).

Adicionalmente, hay que señalar la adopción, en julio de 2015, de la ley relativa a los servicios de inteligencia franceses, con el propósito de definir el marco legal dentro del cual estos están autorizados a hacer uso de técnicas de acceso a la información. De hecho, un informe parlamentario de mayo del 2013 había mostrado que estas agencias actuaban sin base legal y carecían de un control jurídico. . En este sentido, el texto somete la utilización de técnicas de inteligencia a una autorización del primer ministro, tras la opinión de una autoridad administrativa independiente, la Comisión Nacional de Control de las Técnicas de Inteligencia (cnctr, por su sigla en francés). Tales técnicas, ya autorizadas en el marco jurídico, fueron extendidas a los servicios de inteligencia, entre las cuales se puede señalar la utilización de rastreador de vehículos, instalación de micrófonos en lugares privados, captura de imágenes en lugares privados, captura de datos informáticos, acceso a las redes de operadores de telecomunicaciones para monitorear a personas identificadas como representantes de una amenaza terrorista.

Sin embargo, dichas técnicas solo podrán ser utilizadas para finalidades enumeradas por la ley, como la seguridad nacional, los intereses esenciales de la política exterior y la ejecución de los compromisos internacionales de Francia, sus intereses económicos y científicos esenciales y la prevención del terrorismo, entre otros.

Como se mencionó anteriormente, la ola de ataques terroristas en el territorio francés durante los últimos años ha llevado el Gobierno a tomar medidas excepcionales para fortalecer su seguridad interior, entre estas la declaración de estado de emergencia. Tal disposición fue instaurada mediante una ley de 1955, y modificada en 1960, para permitir su declaración por el Consejo de Ministros (la ley inicial solo permitía la declaración del estado de emergencia por el Parlamento). Sin embargo, su prolongación más allá de doce días tiene que ser ratificada por el Parlamento y su aplicación limitada a los casos de peligro inminente como resultado 
de graves violaciones del orden público, o de calamidad pública (desastre natural de excepcional magnitud). El 20 de noviembre de 2015, tras los atentados de París, se decreta el estado de emergencia, que fue prolongado por tres meses a partir del 26 de noviembre y de manera sucesiva hasta el primero de noviembre del 2017.

El 30 de octubre del 2017 se promulga la ley de seguridad interior y de lucha contra el terrorismo que marca el fin y, al mismo tiempo, la continuidad del estado de emergencia. De hecho, el texto marca el fin de la aplicación de varias medidas del estado de emergencia (la posibilidad de cerrar teatros, lugares de venta de licores y lugares de reunión, así como la interdicción de marchas).

Sin embargo, la ley integra en el derecho común disposiciones que hasta ahí estaban reservadas al estado de emergencia. Entre estas medidas se puede señalar que el prefecto (préfet), representante del Estado en el departamento, tendrá la competencia de establecer perímetros de protección, reservados a lugares o eventos que representan un riesgo de actos de terrorismo por su naturaleza misma o por la amplitud de frecuentación. Igualmente, el prefecto podrá resolver del cierre administrativo de lugares de culto por apología o provocación al terrorismo y podrá ordenar, bajo la autorización de un juez, la visita de cualquier lugar cuando existen razones serias para pensar que dicho lugar está frecuentado por un individuo sospechoso de terrorismo (Vie Publique, 2017).

El ministro del Interior podrá decidir medidas de vigilancia contra cualquier persona por la cual existan razones serias de pensar que su comportamiento representa una amenaza particularmente grave a la seguridad y al orden público. El ministro también podrá exigir a tal persona permanecer dentro de un perímetro determinado (que no puede ser inferior al municipio). Finalmente, hay que resaltar que la nueva ley de seguridad interior amplía las posibilidades de control en áreas fronterizas (esto incluye puertos, aeropuertos y estaciones ferroviarias o viales, abiertas al tráfico internacional) para controlar mejor la inmigración y prevenir actos de terrorismo (Vie Publique, 2017).

Hay que indicar que, durante los debates que condujeron a la adopción la nueva norma, algunos diputados expresaron su inquietud respecto a tales medidas que, según ellos, juegan el juego de los terroristas y llevan a la sociedad francesa a aceptar disposiciones que van en contra de los principios republicanos y reducen las libertades fundamentales de la Constitución. Estas alarmas han surgido en varios de los países que se han enfrentado a la amenaza terrorista e ilustran la constante preocupación por el equilibrio entre la necesidad de defenderse contra la amenaza terrorista y la voluntad de mantener y proteger los principios esenciales de las democracias modernas. 


\section{I.3 LAS Misiones de las Fuerzas Armadas: UNA Mirada haCia}

\section{EL EXTERIOR}

El rol principal del ministerio de Defensa es garantizar la protección del territorio, de la población y de los intereses franceses, pero de igual forma responde a otras misiones (figura 6) en el marco de los acuerdos internacionales, como la otan, y de los acuerdos regionales (Ministère des Armées, 2018b). Se involucra también en misiones del servicio público, apoyando las acciones de otros ministerios en el territorio nacional o en el extranjero. De acuerdo con los lineamientos del ministerio de Defensa, las misiones de las Fuerzas Armadas se pueden catalogar así:

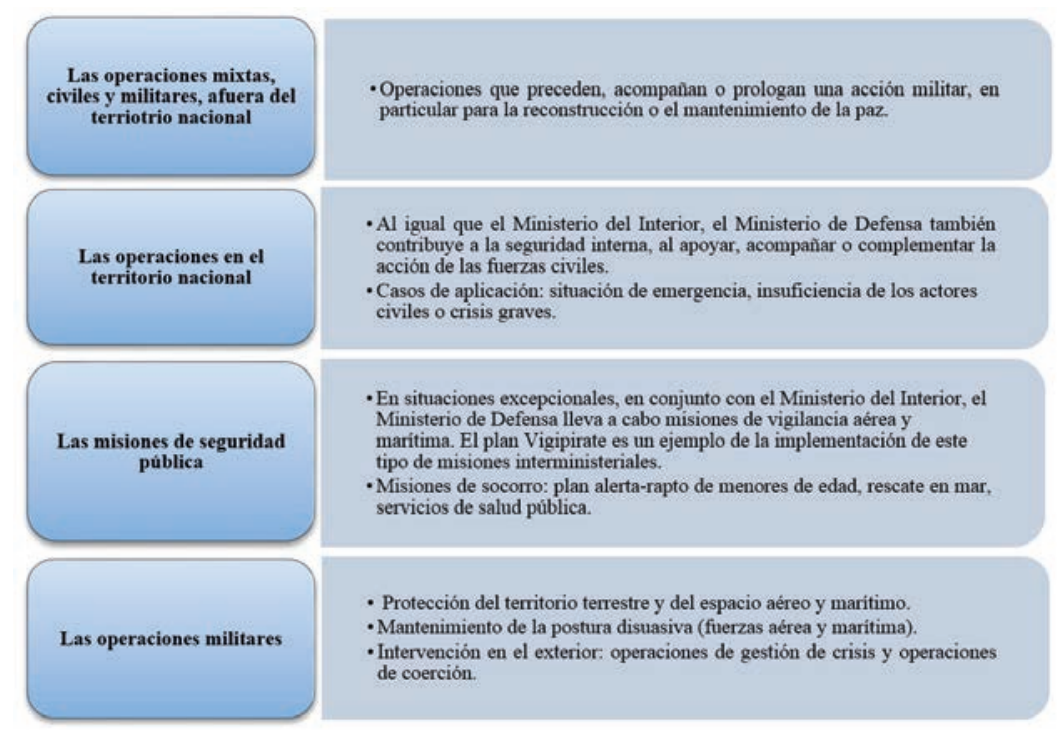

Figura 6. Misiones de las Fuerzas Militares francesas.

Fuente: Elaboración propia con información del Ministerio de Defensa.

Teniendo en cuenta los compromisos internacionales de Francia, se deben ejecutar misiones de intervención no permanentes más allá de las fronteras, de este modo no solo desarrolla capacidades para responder a las crisis internacionales, sino que también participa e interviene en más de una operación de gestión de crisis, de esta forma consigue actuar en varios teatros de operaciones (The French White Paper on Defence and National Security, 2013).

En este orden de ideas, es importante tener en cuenta que la nueva estrategia de seguridad y defensa nacional del 2013 contó con 20.900 efectivos apostados en el extranjero, de tal forma que 7400 se encontraban en los territorios de ultramar; 4000 debían cumplir misiones especiales en países que antiguamente fueron colo- 
nias francesas, como Senegal, Gabón y Djibuti; 400 soldados participaron en operaciones militares en Malí, Chad, la República Centroafricana, Costa de Marfil, el Golfo, Guinea y Jordania; y 3100 participaron en misiones conjuntas con la otan y la ue (abc Internacional, 2014).

\subsection{Las capacidades del sector defensa: continuidad y modernización}

Una de las herramientas desarrolladas e implementadas desde la década de los sesenta en materia de seguridad y defensa es la Ley de Programación Militar (lpm), la cual es emitida por un periodo de cinco años, en ella se establecen las principales directrices para el periodo considerado y se regulan las inversiones en defensa para satisfacer tres misiones asignadas a las Fuerzas Armadas, las cuales radican en: protección de Francia y de sus ciudadanos; disuasión nuclear; e intervención en el exterior (Calvo, 2014). La lpm 2009-2014 ha permitido una continuación en el proceso modernizador de las capacidades militares de Francia y ha contribuido al buen desempeño de tas intervenciones en Costa de Marfil y Libia, en el 2011, y de Malí, en el 2013 (The French White Paper on Defense and National Security, 2013), como estrategia para apoyar la solución de crisis en zonas periféricas del continente europeo.

La Ley de Programación Militar 2014-2019 confronta la necesidad de la renovación del equipo principal y el mantenimiento de las capacidades operacionales, con el fin de mejorar la efectividad de las fuerzas armadas y ante un restablecimiento de la balanza presupuestaria de las finanzas públicas (The French White Paper on Defense and National Security, 2013). El proceso de constante perfeccionamiento de las capacidades de las misiones permanentes se desarrolla de forma articulada con una de las acciones estratégicas establecidas: la disuasión, mediante la cual se han modernizado las capacidades aéreas y marítimas. En este sentido, las fuerzas armadas logran vincular alrededor de 10.000 miembros de las fuerzas terrestres con los recursos apropiados provistos por la naval y la fuerza aérea (The French White Paper on Defense and National Security, 2013).

Adicionalmente, en busca de garantizar la autonomía estratégica en casos de crisis, se determina que se contará con una fuerza de emergencia nacional de 5000 efectivos en espera, lo que le permitirá al Estado francés constituir una Fuerza Conjunta de Reacción Inmediata (firi) de 2300 efectivos, con la capacidad para movilizarse y de intervenir en un radio de 3000 kilómetros desde el territorio nacional o a partir de una base extranjera, en siete días (The French White Paper on Defense and National Security, 2013). De acuerdo con el Libro blanco francés, esta fuerza conjunta, firi, estará compuesta por un conjunto de fuerzas especiales 
integradas por un conjunto de tierra combinado de 1500 hombres equipados con vehículos blindados y helicópteros; un grupo naval que consta de un buque de comando (bpc), 10 aviones de combate, transporte táctico de aviones, aviones de patrulla marítima y aviones de reabastecimiento de combustible aire-aire (The French White Paper on Defense and National Security, 2013).

De igual forma, $y$ sin dejar de lado las tareas operativas existentes, las fuerzas armadas francesas deben desarrollar la capacidad de poder actuar con una coalición en teatros de operaciones coercitivos, donde los combates pueden ser de alta intensidad, además, posee la habilidad y capacidad para asumir el comando completo o parcial de la operación. En este sentido, Francia debe tener la capacidad para proveer importantes recursos, tales como fuerzas especiales, brigadas terrestres, aviones de combate, portaviones, un submarino de ataque nuclear y recursos para garantizar las funciones de comando (The French White Paper on Defense and National Security, 2013). Gracias al proceso modernizador de las fuerzas armadas francesas durante los últimos años, se espera que para el 2025 hayan desarrollado capacidades de mando y control que les permitan garantizar el comando operativo y el control nacional de las fuerzas desplegadas, así como lograr el desarrollo de operaciones de forma autónoma (The French White Paper on Defence and National Security, 2013).

Por último, hay que señalar la importancia de la Gendarmería Nacional, la cual es una fuerza adjudicada al Ministerio del Interior, empleada en el desarrollo de misiones de seguridad interna, en particular en áreas rurales y periurbanas. Es un activo importante debido a su estatuto militar y su presencia en todo el territorio. Sus capacidades y habilidades pueden complementar las acciones de las fuerzas armadas por medio de recursos como helicópteros, vehículos acorazados y una red de transmisión de seguridad nacional. Así mismo, el soporte prestado a las fuerzas armadas es esencial, debido a las unidades especializadas de la gendarmería (mar, aire, armamento, seguridad de armas nucleares), al servicio de policía militar y su continua participación en operaciones externas (The French White Paper on Defence and National Security, 2013).

\section{Desafíos presupuestales del sector defensa}

La crisis económica del 2008 tuvo un fuerte impacto en el presupuesto de la defensa, que se ha visto afectado de forma directa debido a la congelación de los gastos autorizados bajo los mandatos de Nicolas Sarkozy y François Hollande, con el objetivo de reequilibrar las finanzas públicas. 
Entre los años 2008 y 2014 se aplicó un recorte de 54.000 empleos en el área de defensa, el personal militar pasó de 271.000 a 224.000 efectivos, lo que corresponde a una reducción del 17\% de los efectivos de las fuerzas terrestres, $24 \%$ de la fuerza aérea y $11 \%$ de la marina (abc Internacional, 2014). De acuerdo con las cifras expuestas por el Banco Mundial (figura 7), tras un repunte del gasto militar francés de $2,48 \%$ de su pib, en el 2009, se ha presentado un decrecimiento continuo en esta cartera, que alcanzó su punto más bajo en el 2013 con 2,22\%.

En el 2010 las finanzas públicas plurianuales para el periodo comprendido entre el 2011 y el 2014 representarían un leve decrecimiento en la cartera de defensa frente a lo que se había proyectado, lo que afectó directamente el proceso de modernización y mantenimiento de la infraestructura militar y llegó a obstaculizar el cumplimiento de los objetivos del Libro blanco del 2008 (The French White Paper on Defense and National Security, 2013).

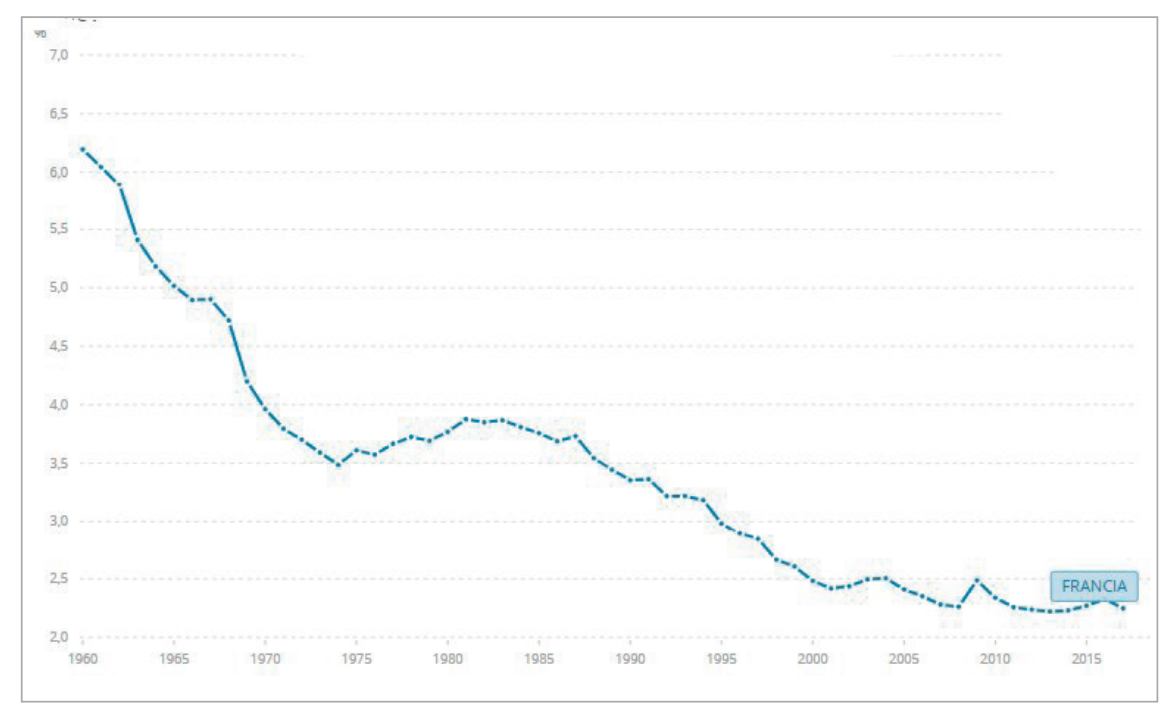

Figura 7. Evolución del gasto militar en Francia.

Fuente: Banco Mundial (2018).

Por otra parte, se estableció que el gasto de defensa para el periodo comprendido entre el 2014 y el 2025 se incrementaría alrededor de 364 mil millones de euros, de los cuales se destinarían 179 mil millones para la implementación de la Ley de Programación Militar 2014-2019 (The French White Paper on Defense and National Security, 2013). No obstante, pese al incremento establecido en el presupuesto en la lpm, para el periodo comprendido entre el 2015 y el 2019, la reducción de personal en el Ministerio de Defensa ascenderá a 6918 empleados (lmp 2014-2019, 2013). 
Sin embargo, tras los ataques de enero del 2015 en París, y la nueva dirección adoptada en materia de defensa, se aprueba la ley del 28 de julio, que viene actualizar la lpm 2014-2019. Tal actualización evidencia un esfuerzo importante que asciende a 162,4 mil millones de euros para el periodo 2015-2019, lo que representa un aumento de 3,8 mil millones respecto a la trayectoria inicial de la $1 \mathrm{mp}$ (Ministère des Armées, 2016). Este impulso financiero está destinado a consolidar la función de protección de la estrategia de seguridad nacional, cumplir con el mantenimiento programado de los materiales y apoyar las operaciones de armamento. Paralelamente, se establece una disminución de 14.925 empleos en el sector defensa, en vez de los 33.675 inicialmente previstos, y se ratifica la creación de 15.399 empleos para reforzar el personal dedicado a la protección, en particular el de la Fuerza Operación Terrestre y el de los efectivos de las agencias de inteligencia y de ciberdefensa (Projet de loi Actualisation de la Programation Militaire 20142019). De igual forma, el Gobierno respaldará el reforzamiento de la policía y la gendarmería con la llegada de 5000 nuevos efectivos, y del Ministerio de Justicia y el Servicio de Aduanas con 3500 nuevos empleados que se vincularán a los 2650 cargos suplementarios (Schaeffer, 2015).

\section{Orientación después del 2015: un freno a los recortes presupuestales y nuevas adquisiciones}

En los lineamientos de la ley de actualización de la lpm 2014-2019, se aprueba también un esfuerzo significativo con respecto a los equipamientos y la disponibilidad de los materiales. Por lo anterior, se avala la disponibilidad de siete helicópteros Tigre y seis helicópteros nh90/tth adicionales; la adquisición junto con Alemania de un tercer satélite de observación espacial musis, así como la adquisición de una carga útil roem sobre dron Reaper. Para las Fuerzas Especiales se autoriza el armamento de dos C130 y la renovación del parque de binoculares de visión nocturna.

Respecto a los medios navales, se decide adelantar el programa "Fragatas de tamaño intermediario" (fti), la adquisición de un edificio multimisión (batiment multimission, b2m) adicional y de cuatro edificios de apoyo y de asistencia (bsah). Asimismo, para la Fuerza Aérea, se dispone de la anticipación de la entrega de los tres últimos aviones abastecedores mrtt, el estudio de la disponibilidad de cuatro C130, la adquisición de 25 pods talios adicionales para el Rafale y el Mirage 2000D. Finalmente, se adopta un presupuesto de 500 millones de euros para llevar a cabo el mantenimiento y la renovación de los equipos. 
De igual forma, conforme a lo expuesto en el Libro blanco de seguridad y defensa nacionales del 2013, se proyecta la configuración de la estructura de las fuerzas armadas y la funcionalidad de sus componentes. Las fuerzas especiales se identifican como el mecanismo adecuado para la reacción frente a una amenaza hostil y se refuerzan sus recursos de personal y de comando, así como la coordinación con los servicios de inteligencia, la Dirección General de la Seguridad Exterior (dgse) y la Dirección General de Seguridad Interior (dgsi). De igual forma, se establecen los escenarios para el funcionamiento de las fuerzas terrestres, la naval, la fuerza aérea y la Gendarmería Nacional.

Por otra parte, la ley de programación militar 2019-2025, elaborada bajo la presidencia actual, se inscribe en la continuidad del esfuerzo presupuestal consagrado en la ley de actualización. De hecho, el presidente Emmanuel Macrón determinó una inversión de 198 mil millones para los próximos cinco años:

Hasta 2022, el presupuesto aumentará de 1,7 mil millones de euros por año y luego de tres mil millones en 2013 elevando el presupuesto de las Fuerzas Militares a 39,6 mil millones de euros por año en promedio, [...] entre 2019 y 2023. Para este periodo, tal esfuerzo representa 7.4 mil millones de euros más por año en promedio en comparación con el periodo 2014-2018 (32,2 mil millones de euros por año). En total, los recursos de las Fuerzas Militares aumentan en casi un cuarto (23\%). Esta contribución financiera excepcional a favor del sector defensa ilustra el compromiso del presidente actual de elevar el esfuerzo de defensa a $2 \%$ de la riqueza nacional para 2025. (Ministère des Armées, 2018, Synthèse, p. 4)

Para enfrentar el deterioro del contexto de seguridad internacional y la intensificación de los compromisos, la lpm 2019-2025 se enfoca hacia el bienestar del personal militar y de sus familias (capacitación, preparación operacional, equipamientos, entrenamiento, condiciones de vida, infraestructuras); la renovación de las capacidades operacionales (modernización equipos convencionales); mantenimiento de la autonomía francesa y construcción de una autonomía estratégica europea (capacidades con valor agregado: inteligencia, ciberdefensa y capacidades de mando, entre otros) y el apoyo a la innovación, investigación y desarrollo de las nuevas tecnologías.

\section{Estructura militar de la defensa}

El Instituto Español de Estudios Estratégicos (ieee), asociado al Ministerio de Defensa español, estudió las estructuras de seguridad de algunos países europeos en su publicación titulada En busca de una Estrategia de Seguridad Nacional 
(Ballesteros, 2016). Respecto a la estructura de seguridad francesa (figuras 8 y 9), soportada en la V Constitución de la República francesa y el Código de la Defensa, se puede identificar la siguiente estructura (Ballesteros, 2016):

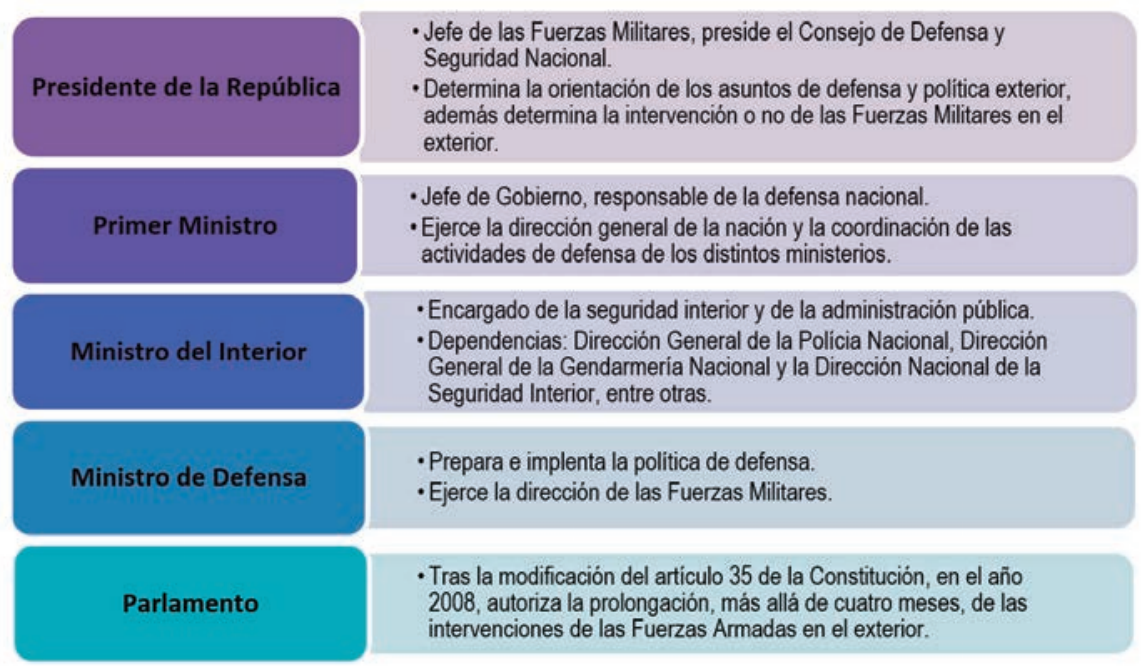

Figura 8. Organización de los poderes en materia de defensa y seguridad. Fuente: Elaboración propia con información del Ministere des Armées (2018).

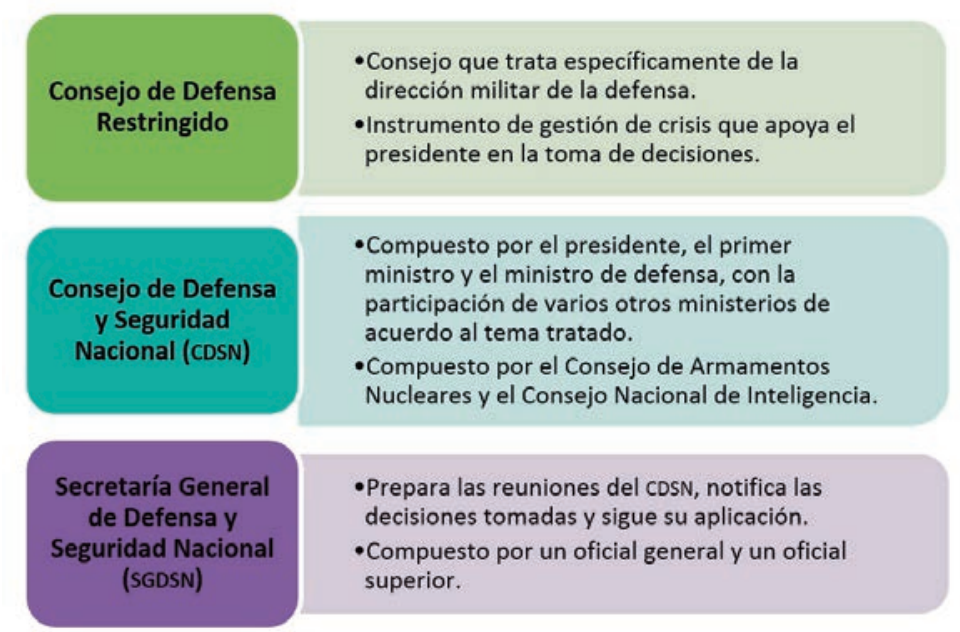

Figura 9. Otras instituciones claves de la defensa y seguridad.

Fuente: Elaboración propia con información del Ministerio de Defensa y Ministerio del Interior.

Dentro de esta estructura de seguridad es importante tener en cuenta que es el Ministerio de Defensa (figura 10) el que tiene a su cargo la organización y dirección 
de las Fuerzas Armadas. Dentro de la estructura del ministerio se pueden identificar (Ministére des Amées, 2018):

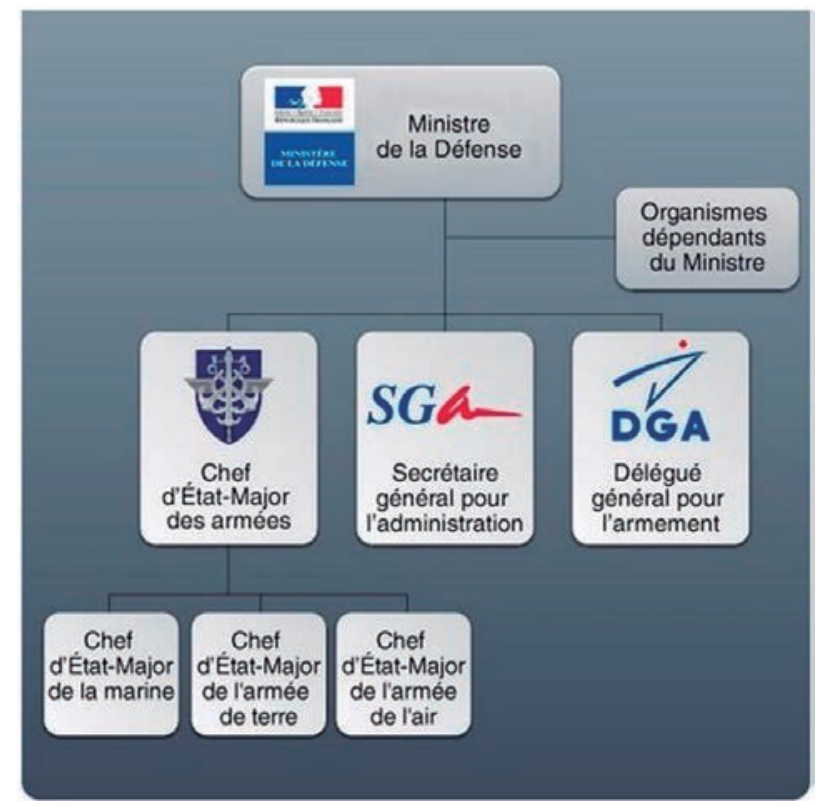

Figura 10. Estructura Ministerio de Defensa Francia.

Fuente: Ministère des Armées, 2017.

El secretario general para la administración (sga) se encarga de la administración de los recursos presupuestarios, financieros, legales, patrimoniales y humanos. El Delegado General para el Armamento (dga), está a cargo de la adquisición de armas y equipamiento para las Fuerzas Armadas, además, fomenta la inversión en investigación en defensa, el desarrollo del programa de armas y promueve la exportación de estas.

El Jefe de Estado Mayor de las Fuerzas Armadas (cema) está a cargo de la organización general de las fuerzas y agencias conjuntas. La estructura militar de la defensa está dividida entre la Fuerza Aérea, la Fuerza Terrestre y la Marina Nacional, cada una de ellas a cargo de un Jefe de Estado Mayor.

\section{La industria de defensa: un apoyo notable para la economía francesa}

La industria de defensa es un factor clave para la autonomía estratégica francesa, lo que contribuye de forma coherente a sus ambiciones políticas, diplomáticas 
y económicas. Además, tiene la capacidad de garantizar el suministro de los equipos y sistemas de armamento crítico que respaldan su soberanía, lo que coincide con lo dispuesto por el Ministerio de Defensa (The French White Paper on Defense and National Security, 2013). Es por esto que el gobierno francés continúa el proceso de modernización en inversión el en sector de defensa, pese a los obstáculos presupuestarios derivados de la crisis financiera del 2008. Por lo anterior, el sector de defensa ocupa un lugar importante en las finanzas públicas y se mantiene como el segundo presupuesto militar europeo, tras Reino Unido, lo que confirma sus ambiciones y su doctrina de autonomía estratégica (Fuente, 2016).

Este prestigio, adquirido en el sistema internacional, es resultado del inminente apoyo brindado por el Estado, representado por el Ministerio de Defensa en el fomento para la innovación industrial y tecnológica en el sector defensa. El Ministerio de Defensa en el 2016 dispuso de 3800 millones de euros en investigación y desarrollo, 1550 millones en estudios de defensa, 855 millones en investigación y tecnología y 707 millones en contratos de demostraciones de tecnología (figura 11) (Les chiffres clés de la Défense, 2016), esto refleja el interés y la voluntad del Gobierno por continuar el proceso de modernización y garantizar la independencia estratégica.

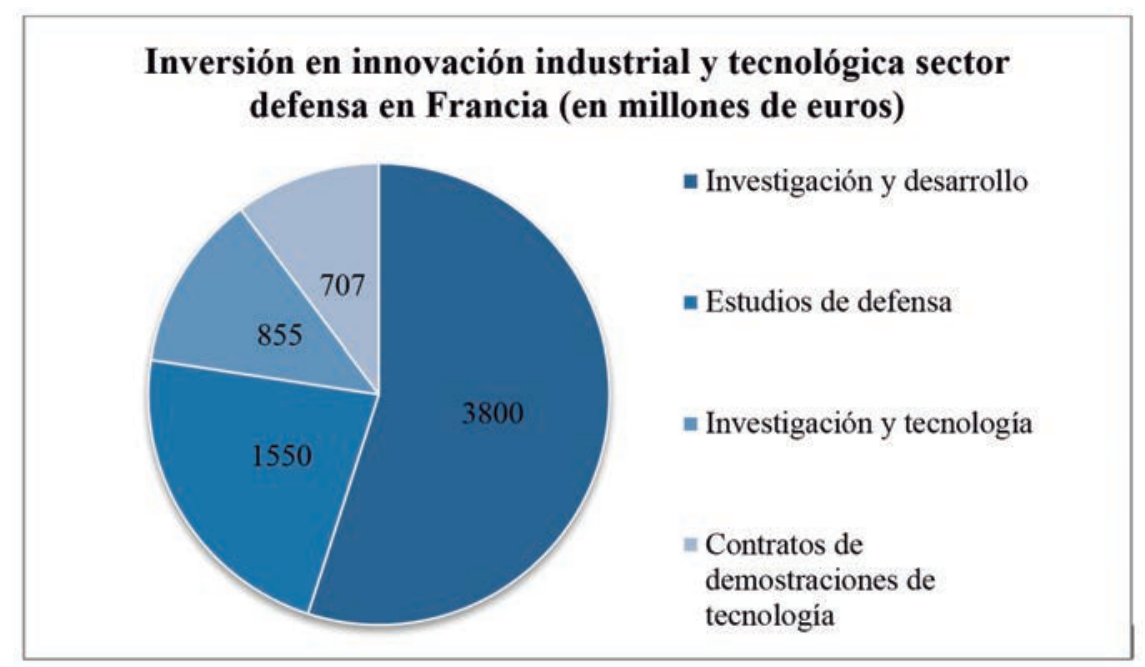

Figura 11. Inversión Sector Defensa Francia. 2016

Fuente: Elaboración propia con información del Ministerio de Defensa.

Esta industria también hace una gran contribución a la economía francesa y se posiciona como una de las mejores a nivel global, con calidad de exportador debido 
a que exporta entre el 25\% y el 40\% de su producción, lo que contribuye positivamente a la balanza comercial. La industria de defensa francesa está compuesta por alrededor de 4000 compañías, de las cuales las más reconocidas y mejor clasificadas dado su importante contribución son: Dassault Aviation; Naval Group; Airbus Group; mbda; Nexter; Thales y Safran, además de estas, existe una gran cantidad de pequeñas y medianas empresas, las cuales generan unos ingresos aproximados de 15 mil millones de euros y emplean cerca de 150.000 trabajadores, lo que incluye a 20.000 expertos calificados (figura 12) (The French White Paper on Defense and National Security, 2013).

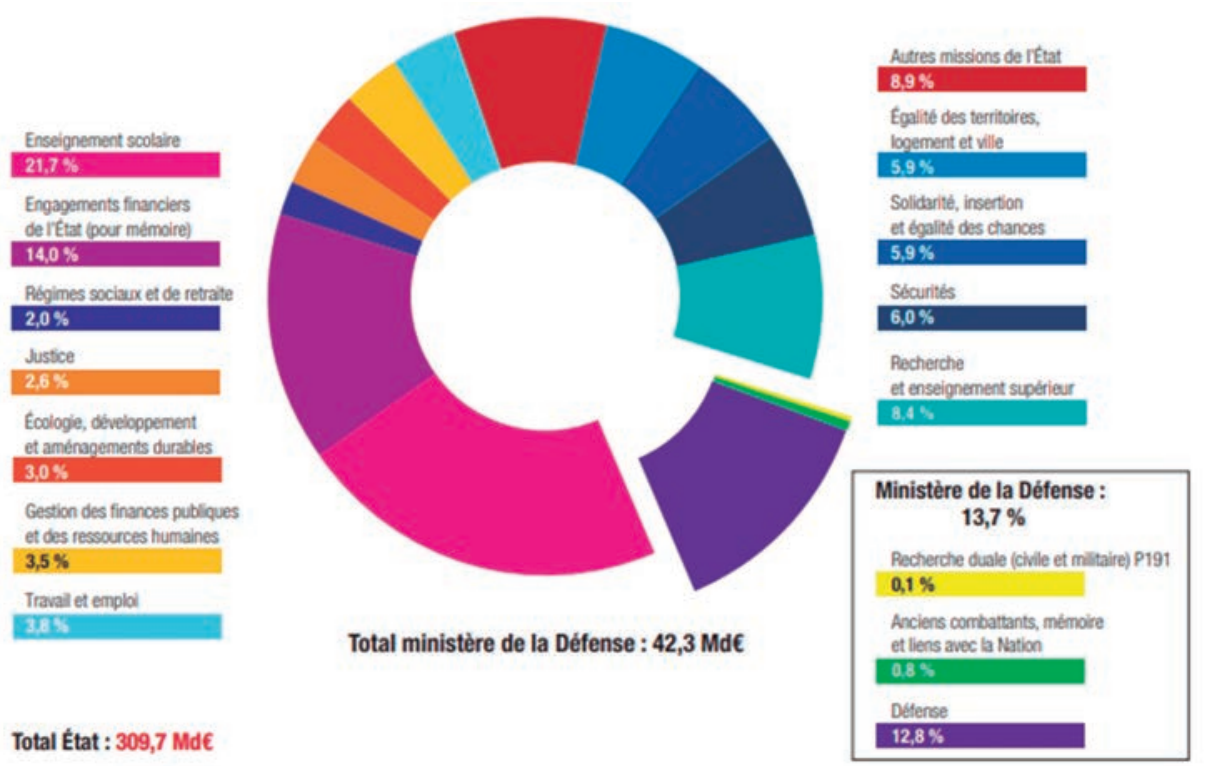

Figura 12. Presupuesto Ministerio de Defensa dentro del presupuesto total. Fuente: Les chiffres clés de la Défense (2016).

En la medida en que el sector defensa se vuelve más competitivo a nivel regional e internacional (figura 13), va adquiriendo nuevas capacidades para entrar en otros mercados y fomenta la producción tanto como la exportación de material de guerra (mg) (Observatoire économique de la défense, 2017). Así mismo, esta competitividad consolida la doctrina de la autonomía estratégica, en el sentido en que Francia deja de ser interdependiente de sus socios y aliados, lo que le permite desarrollar capacidades de reacción inmediatas. De igual forma, Francia accede por sus propios medios a capacidades y armamento moderno e innovador que podrán garantizar la seguridad nacional y el bienestar de la población. 


\begin{tabular}{|c|c|c|c|c|c|}
\cline { 2 - 6 } & \begin{tabular}{|c|c|c|c|} 
Encargos de \\
MG para la \\
exportación
\end{tabular} & $\begin{array}{l}\text { Tasa de cre- } \\
\text { cimiento de } \\
\text { los encargos } \\
\text { (en \%) }\end{array}$ & $\begin{array}{l}\text { Entregas de } \\
\text { MG para la } \\
\text { exportación }\end{array}$ & $\begin{array}{l}\text { Tasa de cre- } \\
\text { cimiento de } \\
\text { las entregas } \\
\text { (en \%) }\end{array}$ & $\begin{array}{l}\text { Entregas de } \\
\text { MG para la } \\
\text { importación }\end{array}$ \\
\hline $\mathbf{2 0 1 2}$ & 4817 & -26 & 5740 & 7 & 1550 \\
\hline $\mathbf{2 0 1 3}$ & 6874 & 43 & 5723 & -0.3 & 1511 \\
\hline $\mathbf{2 0 1 4}$ & 8218 & 20 & 6131 & 7 & 1708 \\
\hline $\mathbf{2 0 1 5}$ & 16922 & 106 & 7270 & 19 & 1663 \\
\hline $\mathbf{2 0 1 6}$ & 13943 & -18 & 8308 & 14 & 1704 \\
\hline $\begin{array}{l}\text { Promedio } \\
\mathbf{2 0 1 2 / 2 0 1 6}\end{array}$ & $\mathbf{1 0} \mathbf{1 5 5}$ & $\mathbf{3 0}$ & $\mathbf{6 6 3 4}$ & $\mathbf{1 0}$ & $\mathbf{1 6 2 7}$ \\
\hline
\end{tabular}

Campo: materiales de guerra (MG) y materiales asimilados.

Fuentes: Informe al Parlamento sobre las exportaciones de armamento de Francia para los encargos; base de datos de la Dirección Nacional de estadísticas del comercio exterior (DNSCE) para las entregas.

Figura 13. Importación y exportación de material de guerra en Francia.

Fuente: Anuario Estadístico de Defensa. Ministère des Armées (sga, 2017).

Por otra parte, el fortalecimiento de la industria de defensa puede garantizar mayor eficacia en la implementación de la estrategia de defensa y seguridad nacional, lo que se puede materializar en el establecimiento de una relativa seguridad y podría llegar a proyectar al país como un centro atractivo para la inversión y el desarrollo de nuevas infraestructuras.

\section{Conclusiones}

La estrategia de seguridad y defensa nacional francesa se ha desarrollado en un escenario globalizado en el cual la identificación de las amenazas y su naturaleza se vuelve cada vez es más difícil. No obstante, la estrategia expuesta en el Libro blanco del 2013 permite una aproximación a la identificación de las amenazas tradicionales y a las nuevas amenazas, así como a los riesgos internos y externos que tienen el potencial de atentar contra la integridad del Estado y el bienestar de la población. De igual forma, la estrategia permite ahondar en las dimensiones de las amenazas, con el objeto de organizar e implementar mecanismos de respuesta a nivel nacional e internacional y con el fin de demostrar la voluntad que tiene el Estado en relación a mantener y respetar los compromisos y responsabilidades internacionales.

Dentro del proceso de la elaboración de las estrategias de defensa y seguridad nacional se puede considerar que existe una consolidación de la estrategia por la continuidad bajo la cual se ha desarrollado. La articulación entre los postulados 
del Libro blanco del 2008 y del 2013 respecto al concepto de seguridad y acciones estratégicas brinda una aproximación a esta consolidación. La continuidad y articulación que se han sostenido permitieron adquirir nuevos conocimientos con respecto a las amenazas y los riesgos, esto permitió desarrollar nuevos mecanismos de respuesta y modernizar tanto las capacidades militares como su dotación. Un factor clave que contribuye a la consolidación de la estrategia radica en la diferenciación entre amenazas y riesgos, lo que permite un mayor margen de maniobra en la redirección de los esfuerzos y recursos de la defensa nacional.

La estrategia formulada en el 2013 permite realizar un análisis más profundo de las amenazas y su posterior clasificación en tres niveles: amenazas de la fuerza, riesgo de debilidad y amenazas y riesgos amplificados de la globalización, lo que permite conocer de fondo las causas de las amenazas y su modo de operación, además, hace posible conocer de manera anticipada mecanismos estratégicos de respuesta ante cualquier tipo de amenaza, gracias a la preparación y modernización de las fuerzas militares.

También se puede establecer que la adopción de las cinco acciones estratégicas del 2008 permite una mayor preparación por parte de las instituciones del Estado en materia de defensa. La adopción de las acciones estratégicas y la identificación de las amenazas permiten establecer con mayor claridad los mecanismos para garantizar las prioridades estratégicas más coherentes con los objetivos nacionales y las responsabilidades internacionales.

Pese al esfuerzo del Gobierno nacional de Francia en la implementación de las estrategias de defensa y seguridad nacional, el país no es ajeno a las amenazas del sistema internacional, ni a los riesgos de la globalización. La crisis económica del 2008 afectó de manera profunda el sector de defensa, lo que generó recortes de personal y de presupuesto, además, limitó la capacidad de acción a nivel local, regional e internacional y obstaculizó uno de sus principales objetivos, la autonomía estratégica.

Resulta claro que para los últimos gobiernos franceses, el desarrollo de las capacidades militares es un objetivo estratégico, lo cual se ve reflejado en las medidas fiscales y de finanzas públicas tomadas tras los atentados del 2015, mediante las cuales se replantea el gasto de la cartera de Defensa y se reforma la Ley de Programación Militar, con el fin de aumentar el gasto presupuestado y congelar los recortes de personal, lo que demuestra voluntad y capacidad en el escenario nacional e internacional frente a las responsabilidades adquiridas.

La industria de la defensa es un sector clave para el desarrollo y la innovación militar, así como para la económica nacional, ya que el Estado francés respalda y 
promueve con gran ímpetu el sector, pues impulsa desde pequeñas empresas hasta enormes industrias que dejan como resultado grandes avances tecnológicos en materia de defensa.

Finalmente, se puede concluir que el proceso de formulación de la estrategia de defensa y seguridad nacional debe seguir siendo articulada de forma continua. Sin embargo, se debe reevaluar continuamente la naturaleza de las amenazas y de los riesgos, así como las capacidades de respuesta, con el fin de reafirmar su voluntad frente al cumplimiento de los compromisos multilaterales y de responder ante sus responsabilidades y compromisos, sin olvidar mantener siempre su autonomía estratégica y conservar su estatus en el sistema internacional.

Lo anterior, con el objetivo de habilitar y preparar a Francia para enfrentar las nuevas amenazas terroristas, las cuales permanecen latentes —como quedó demostrado tras los ataques del 2015-, por lo cual se debe mantener el proceso de modernización y de fortalecimiento de las fuerzas militares. Así mismo, si el Estado francés desea mantener su estatus en el sistema internacional debe fortalecer el sector de la industria de la defensa mediante el posicionamiento de las empresas del sector en el mercado internacional y el incremento de las exportaciones de material de guerra, con lo que conseguiría aumentar sus ingresos y contrarrestar el déficit fiscal.

Por otra parte, Francia debe prestar atención a la dinámica política internacional y tomar en cuenta el reposicionamiento ruso y chino en el sistema internacional en materia política, militar y económica. En consecuencia, debe fortalecer sus compromisos multilaterales y mantener su estatus e influencia tanto en los territorios de ultramar como en las regiones donde tradicionalmente ha tenido presencia.

Para el caso colombiano, se recomienda hacer una revisión conceptual teniendo en cuenta las particularidades de la coyuntura nacional. Una de las particularidades más representativas del caso colombiano está relacionada con la naturaleza del conflicto interno, por esta razón es importante determinar e identificar cuáles son los riesgos y las amenazas para la defensa y la seguridad nacionales, con el fin de desarrollar nuevos mecanismos y capacidades de respuesta.

De igual forma, la naturaleza del conflicto armado en Colombia ha permitido la interacción de diversas amenazas y riesgos, propios de la globalización, que han permeando las fronteras nacionales y aumentado las vulnerabilidades ante el sistema internacional. De acuerdo a este escenario, se debería hacer una valoración frente a la adopción de acciones estratégicas como la protección, conocimiento y anticipación, prevención, y por qué no, intervención, para explotar de este modo las capacidades y experiencias desarrolladas a lo largo del tiempo en las luchas contra 
las amenazas internas (Chavarro Miranda, Grautoff Laverde \& Riaño Cruz, 2017). Igualmente, sería pertinente hacer una revisión del estado del sector defensa y establecer estrategias para su modernización y ampliación, con el fin de desarrollar un nuevo papel en el sistema internacional.

\section{Referencias}

Álvarez Calderón, C., \& Rodríguez Beltrán, C. (2018). Ecosistemas criminales. Revista Científica General José María Córdova, 16(24), 1-30. https://doi.org/10.21830/19006586.352

Aron, R. (1985). Paz y Guerra entre las Naciones. Madrid: Alianza.

Arteaga, F. (21 de Octubre de 2008). El concepto de seguridad nacional en el Libro Blanco de la Defensa y la Seguridad Nacional de Francia. Recuperado el 14 de Enero de 2018, de Real Instituto Elcano: http:// www.realinstitutoelcano.org/wps/portal/!ut/p/a0/04Sj9CPykssy0xPLMnMz0vMAfGjzOKNg318fEKcHX1NTZz9QgKNXI0NDSBAvyDbUREAbg0Kqw!!/?WCM_PORTLET=PC_ Z7_3SLLLTCAM54CNTQ27F30000000000000_WCM\&WCM_GLOBAL_CONTEXT=/ wps/wcm/connect/elcano/elcano_es/zonas_es/ari13

Ballesteros Martín, M. (18 de Agosto de 2006). El papel de las fuerzas armadas en la lucha contre el terrorismo internacional.Recuperadoel20deEnerode2018, deReal InstitutoElcano:http://www.realinstitutoelcano.org/wps/portal/!ut/p/a0/04_Sj9CPykssy0xPLMnMz0vMAfGjzOKNg318fEKcHX1NTZ

z9QgKNXI0NDSBAvyDbUREAbg0Kqw!!/?WCM_GLOBAL_CONTEXT=/wps/wcm/connect/ elcano/elcano_es/zonas_es/ari+91-2006

Ballesteros Martín, M. (2016). En busca de una Estrategia de Seguridad Nacional. (M. d. Defensa, Ed.) España.

Banco Mundial. (2018). Recuperado el 30 de Enero de 2018, de Gasto Militar (\% del PIB): https://datos. bancomundial.org/indicador/MS.MIL.XPND.GD.ZS?end=2016\&locations=FR\&start=2000\& view=chart

Brzezinski, Z. (1998). El Gran Tablero Mundial. Paidos Iberica.

Calvo González-Regueral, C. (30 de Enero de 2014). La Ley de la Programación militar francesa. Recuperado el 30 de Enero de 2018, de Observatorio PSyD.: http://catedrapsyd.unizar.es/observatorio-psyd/opina/la-ley-de-programacion-militar-francesa.html

Cardone, I. (Julio/Septiembre de 2014). El conflicto en Ucrania: los intereses de las grandes potencias y lo perdedores de siempre. Conjuntura Global, 3(3), 140-148.

Castro Fernandez, S. (22 de Mayo de 2013). La gran recesión. Una mirada desde Europa. Recuperado el 25 de Enero de 2018, de Instituto Español de Estudios Estratégicos: http://www.ieee.es/Galerias/ fichero/docs_analisis/2013/DIEEEA31-2013_GranRecesion_MiradaEuropa_SCF.pdf

Central Intelligence Agency. (2018). The World Factbook. Recuperado el 5 de Enero de 2018, de https:// www.cia.gov/library/publications/the-world-factbook/geos/fr.html

Chavarro Miranda, F., Grautoff Laverde, M., \& Riaño Cruz, J. (2017). Modelo de crecimiento económico y gasto público focalizado en seguridad: enfoque desde la estrategia militar en Colombia (2002-2009). Revista Científica General José María Córdova, 15(20), 27-45. https://doi. org/10.21830/19006586.174 
CGFM. (1996). Manual de Seguridad y Defensa Nacional (Primera Edición ed.). Colombia.

Daguzan, J.-F. (22 de Diciembre de 2008). Real Instituto Elcano. Recuperado el 26 de Enero de 2018, de El terrorismo islámico en Francia: http://www.realinstitutoelcano.org/wps/wcm/connect/bed4df804f0198fa902ef43170baead1/ARI166-2008_Daguzan_terrorismo_islamista_Francia.pdf?MOD=AJPERES\&CACHEID=bed4df804f0198fa902ef43170baead 1

De Salazar Serantes, G. (Octubre de 2004). El sector nuclear ex soviético. El nuevo desafío: la proliferación nuclear en el umbral del siglo XXI(4).

Dufort, P. (2017). La influencia de la comprensión cambiante del poder sobre la estrategia: un ensayo genealógico. Revista Científica General José María Córdova, 15(19), 29-81. https://doi. org/10.21830/19006586.83

European Defence Agency. (2018). Recuperado el 29 de Enero de 2018, de https://www.eda.europa.eu/ Aboutus/who-we-are/member-states

Ferrari, C. (27 de Mayo de 2012). La crisis económica de Europa y el contagio mundial. Recuperado el 28 de Enero de 2018, de Razón Pública: https://www.razonpublica.com/index.php/internacional-temas-32/2995-la-crisis-economica-de-europa-y-el-contagio-mundial.html

Francetvinfo.fr (22 de Feberero de 2016). Gilles Kepel: «Il existe bien un djihad francais qui s'est construit ces dix derniéres années». Recuperado el 22 de junio de 2018 de https://www.francetvinfo. $\mathrm{fr} /$ replay-radio/tout-et-son-contraire/gilles-kepel-il-existe-bien-un-djihad-francais-qui-s-est-construit-ces-dix-dernieres-annees_1776995.html

French White Paper on Defence and National Security. (2013). París, Francia.

Fuente Cobo, I. (2016). La política de defensa de los países de nuestro entorno. (I. E. Ministerio de Defensa, Ed.) Cuadernos de Estrategia(179), 15-58. Recuperado el 30 de Enero de 2018, de Insituto Español de Estudios Estratégicos: http://www.ieee.es/Galerias/fichero/docs_analisis/2016/ DIEEEA14-2016_Revision_Defensa_Francesa_IFC.pdf

González San Ruperto, M. (2001). Las Guerras de la ex Yugoslavia: información y propaganda. Madrid, España: Universidad Complutense de Madrid.

Gouvernement République Francaise. (s.f.). Recuperado el 25 de Enero de 2018, de Risques Prévention des risques majeurs: http://www.gouvernement.fr/risques/comprendre-le-plan-vigipirate

Holsti, K. (1995). Política Mundial: Cambio y Conflicto. México: FCE.

Les chiffres clés de la Défense (2016). Recuperado en https://www.defense.gouv.fr/portail/ministere/organisation-du-ministere-des-armees/les-chiffres-cles-de-la-defense.

Le Monde. (27 de febrero de 2014). Recuperado el 02 de Julio de 2018, de Ukraine: Comprendre les orignes de la crise en 5 minutes: https://www.lemonde.fr/europe/video/2014/02/27/pourquoi-1ukraine-est-elle-tiraillee-entre-europe-et-russie_4375125_3214.html

Le Monde. (12 de Diciembre de 2016). Recuperado el 26 de Enero de 2018, de En France, le plan Vigipirate et ses trois niveaux d'alerte: http://www.lemonde.fr/les-decodeurs/article/2016/12/20/ en-france-le-plan-vigipirate-et-ses-trois-niveaux-d-alerte_5052094_4355770.html

Le Monde. (11 de octubre de 2017). Les députés adoptene définitivement le projet de loi antiterroriste en https://www.lemonde.fr/police-justice/article/2017/10/11/les-deputes-adoptent-definitivement-le-projet-de-loi-antiterroriste_5199579_1653578.html

Le rôle du ministère des Armées. (2018). Recuperado el 2 de Febrero de 2018, de Ministère des Armées: https://www.defense.gouv.fr/portail/ministere/le-role-du-ministere-des-armees 
Leira Neira, G. (2008). Revisión estratégica de la defensa en Francia. (C. S. Ministerio de Defensa, Ed.) Boletin de Información(305), 85-114.

Loi n²017- 1510 du 30 octobre 2017 renforcant la sécurité intérieure et lutte contre le terrorisme. Recuperado de Legifrance en https://www.legifrance.gouv.fr/eli/loi/2017/10/30/INTX1716370L/ jo/texte

Loi de Programmation Militaire 2014-2019. (18 de Diciembre de 2013). Recuperado el 30 de Enero de 2018, de Legifrance: https://www.legifrance.gouv.fr/affichTexte.do;jsessionid=953860F9F7CAEB54BB6802EA5530CAFB.tplgfr40s_1?idSectionTA=LEGISCTA000028340441\&cidTexte=JORFTEXT000028338825\&dateTexte $=20180320$

Los principales atentados que han golpeado el mundo desde el ataque contra las Torres Gemelas. (14 de Noviembre de 2015). Recuperado el 20 de Enero de 2018, de ABC Internacional : http://www. abc.es/internacional/abci-principales-atentados-golpeado-mundo-desde-ataque-contra-torres-gemelas-201511141439_noticia.html

Los recortes de Hollande debilitan el ejército francés. (17 de Octubre de 2014). Recuperado el 30 de Enero de 2018, de ABC Internacional: http://www.abc.es/internacional/20141017/abci-recortes-defensa-francia-201410161931.html

Mikail, B. (Octubre de 2011). Francia y la primavera árabe: una política oportunista. Recuperado el 5 de Febrero de 2018, de FRIDE: http://fride.org/descarga/WP_110_Francia_y_primavera_arabe.pdf

Ministere des Armées (Junio de 2016). Actualisation de la loi de programation militaire (LPM) 20142019.

Ministère de L'Intérieur. (1 de Diciembre de 2016). Le plan Vigipirate. Recuperado el 28 de Enero de 2018, de https://www.interieur.gouv.fr/Archives/Archives-des-dossiers/2016-Dossiers/Securite-lesgrands-plans-d-action/Le-plan-Vigipirate

Ministere de L'Interieur. Organisation. Recuperado el 05 de Julio de 2018, de https://www.interieur.gouv. $\mathrm{fr} /$ Le-ministere/Organisation.

Ministère des Armées. (2018). Ministère. Recuperado el 3 de Febrero de 2018, de https://www.defense. gouv.fr/portail/ministere

Ministére Des Armées. (2018). Opérations. Recuperado el 4 de Febrero de 2018, de https://www.defense. gouv.fr/operations/operations/actualites

Ministere des Armées. (2018). Carte des opérations et missions militaires. Recuperado el 04 de julio 2018, de https://www.defense.gouv.fr/operations/rubriques_complementaires/carte-des-operations-et-missions-militaires

Naím, M. (Diciembre-Enero de 2004). Las cinco guerras de la globalización. Foreign Policy Edición Española, 33-40.

Observatoire économique de la défense. (2017). Annuaire statistique de la défense. Recuperado el 10 de Febrero de 2018, de Ministére de Armées: https://www.defense.gouv.fr/sga/le-sga-en-action/economie-et-statistiques/annuaire-statistique-de-la-defense

OCCAR. (2018). Recuperado el 29 de Enero de 2018, de What is OCCAR?: http://www.occar.int/ about-us

Parlamento Europeo. (2017). Recuperado el 27 de Enero de 2018, de La Política Común de Seguridad y Defensa: http://www.europarl.europa.eu/RegData/etudes/fiches_techniques/2013/060102/04A_ FT(2013)060102_ES.pdf 
Pereira Hernández, C. (2009). El retorno de Francia a la estructura militar de la Alianza. (M. d. Nacional, Ed.) Boletin de Información(312), 7-26.

Projet de loi de Programmation militaire 2014- 2019, synthese, Ministere de la Défense, 2014.

Projet de loi Actualisation de la programmation militaire 2014-2019, dossier thématique, Ministere de la Defense, 2015.

RT. (31 de Mayo de 2015). ¿¿Por qué EE.UU. tiene unas 800 bases militares por todo el mundo? Recuperado el 16 de Enero de 2018, de https://actualidad.rt.com/actualidad/176300-bases-eeuu-mundo-causas

Schaeffer, F. (16 de Noviembre de 2015). Les Echos. Recuperado el 31 de Enero de 2018, de Police, justice, douanes, armée: l'Elysée sort les grands moyens: https://www.lesechos.fr/16/11/2015/lesechos.fr/021483605937_police--justice--douanes--armee---1-elysee-sort-les-grands-moyens.htm\#xtor $=\mathrm{CS} 1-33$

Stockholm International Peace Research Institute (03 de Julio de 2017), Global share of nuclear weapons in January 2017 in Global nuclear weapons: Modernization remains the priority. Recuperado el 02 de Julio de 2018 de https:/www.sipri.org/media/press-release/2017/global-nuclear-weapons-modernization-remains-priority

Tertrais, B. (22 de Noviembre de 2008). El Libro Blanco francés sobre la defensa y la seguridad nacional: hacia unas Fuerzas Armadas más fuertes y eficaces. Recuperado el 12 de Febrero de 2018, de Real Instituto Elcano: http://www.realinstitutoelcano.org/wps/portal/!ut/p/a0/04_Sj9CPykssy0xPL MnMz0vMAfGjzOKNg318fEKcHX1NTZz9QgKNXI0NDSBAvyDbUREAbg0Kqw!!??WCM_ GLOBAL_CONTEXT=/wps/wcm/connect/elcano/elcano_es/zonas_es/ari89-2008

The French White Paper on Defence and National Security. (2008). Paris, Francia: Odile Jacob.

Unión Europea. (2018). Relaciones UE-África. Recuperado el 3 de Febrero de 2018, de Consejo Europeo/ Consejo de la Unión Europea: http://www.consilium.europa.eu/es/policies/eu-africa/

Vie Publique (05 de Enero de 2017), Du Tchad a la Syrie: les interventions extérieures de l'armée francaise depuis 1981. Recuperado en http://www.vie-publique.fr/chronologie/chronos-thematiques/ du-tchad-au-mali-interventions-armee-francaise-depuis-1981.html

Vie Publique (08 de Julio de 2017), Les opérations militaires extérieures de la France. Recuperado en http:// www.vie-publique.fr/actualite/dossier/defense/operations-militaires-exterieures-france-opex.html

Vie Publique (03 de Marzo de 2018), Trente ans de législation antiterroriste. Recuperado en http://www. vie-publique.fr/chronologie/chronos-thematiques/trente-ans-legislation-antiterroriste.html

Vie Publique (31 de octubre de 2017), Loi du 30 octobre 2017 renforcant la sécurité intérieure et la lutte contre le terrorisme. Recuperado en http://www.vie-publique.fr/actualite/panorama/texte-discussion/projet-loi-renforcant-securite-interieure-lutte-contre-terrorisme.html

Wolfers, A. (Diciembre de 1952). "National Security” as an Ambiguos Symbol. Political Science Quarterly, 67(4), 481-502. 